\title{
MASS SPECTROMETRY AND REDOX PROTEOMICS: APPLICATIONS IN DISEASE
}

\author{
D. Allan Butterfield, ${ }^{1}$ * Liqing Gu, ${ }^{2}$ Fabio Di Domenico, ${ }^{1,3}$ and Renã A.S. Robinson ${ }^{2}$ \\ ${ }^{I}$ Department of Chemistry, Center of Membrane Sciences, Sanders-Brown \\ Center on Aging, University of Kentucky, Lexington, Kentucky, 40506 \\ ${ }^{2}$ Department of Chemistry, University of Pittsburgh, Pittsburgh, \\ Pennsylvania, 15260 \\ ${ }^{3}$ Department of Biochemical Sciences, Sapienza University of Rome, \\ Rome, 00139, Italy
}

Received 7 December 2012; revised 7 February 2013; accepted 7 February 2013

Published online 30 September 2013 in Wiley Online Library (wileyonlinelibrary.com). DOI 10.1002/mas.21374

\begin{abstract}
Proteomics techniques are continuously being developed to further understanding of biology and disease. Many of the pathways that are relevant to disease mechanisms rely on the identification of post-translational modifications (PTMs) such as phosphorylation, acetylation, and glycosylation. Much attention has also been focused on oxidative PTMs which include protein carbonyls, protein nitration, and the incorporation of fatty acids and advanced glycation products to amino acid side chains, amongst others. The introduction of these PTMs in the cell can occur due to the attack of reactive oxygen and nitrogen species (ROS and RNS, respectively) on proteins. ROS and RNS can be present as a result of normal metabolic processes as well as external factors such as $U V$ radiation, disease, and environmental toxins. The imbalance of ROS and RNS with antioxidant cellular defenses leads to a state of oxidative stress, which has been implicated in many diseases. Redox proteomics techniques have been used to characterize oxidative PTMs that result as a part of normal cell signaling processes as well as oxidative stress conditions. This review highlights many of the redox proteomics techniques which are currently available for several oxidative PTMs and brings to the reader's attention the application of redox proteomics for understanding disease pathogenesis in neurodegenerative disorders and others such as cancer, kidney, and heart diseases. (C) 2013 Wiley Periodicals, Inc. Mass Spec Rev 33:277-301, 2014
\end{abstract}

Keywords: redox proteomics; proteomics; oxidative PTMs; protein carbonyls; protein nitration; review

\section{INTRODUCTION}

Proteomics offers the simultaneous detection of hundreds to thousands of proteins in a single experiment and can provide important information regarding protein identification, quantification, cellular localization, as well as protein interactions and structures. These capabilities are particularly useful in the context of understanding disease states or for biomarker discovery efforts geared towards early diagnosis. Proteomics also gives insight into post-translational events that occur in the

${ }^{*}$ Corresponding to: D. Allan Butterfield, The Alumni Association Endowed Professor of Biological Chemistry; Director, Center of Membrane Sciences; and Sanders-Brown Center on Aging 249 Chemistry-Physics Building, University of Kentucky, Lexington, KY 40506. E-mail: dabcns@uky.edu cell resulting in post-translational modification (PTM) of proteins. While a majority of proteomics studies focus on wellstudied PTMs such as phosphorylation, glycosylation, and methylation for example, there has been a steady growth of research reports surrounding oxidative PTMs. Investigations of oxidative PTMs that occur in vitro or in vivo are currently being performed using focused redox proteomics techniques. Redox proteomics relies on both gel electrophoresis and liquid chromatography separations of intact proteins or peptides with the final detection of oxidative PTMs occurring from mass spectrometry (MS). This review will highlight redox proteomics techniques that are currently available to study various oxidative PTMs and provide examples of redox proteomics applications to understand disease pathology.

\section{A. Protein Oxidation}

Exposure to reactive oxygen species (ROS) is inevitable for organisms living in an aerobic environment. Increased oxidation evoked by ROS is associated with physiological functions during life. ROS represent a fundamental asset to immune cells in immune system responses against pathogens and also play a physiological role in normal plant cell physiology by triggering specific cascades (D'Alessandro et al., 2011). Nonetheless, in humans oxidative stress (OS) is thought to be involved in disease onset and progression. Indeed, altered oxidation status of proteins is one of the PTMs leading to a severe failure of biological functions and to cell death. Indeed, OS is associated with the onset and pathogenesis of several prominent central nervous system disorders and accumulating evidence suggests that abnormal protein oxidation may play a central role in the development of neurodegenerative diseases such as Alzheimer (AD), Parkinson (PD), and Huntington disease (HD) (Cross et al., 1987; Markesbery, 1997; Butterfield \& Lauderback, 2002; Butterfield et al., 2012). The increased intracellular ROS, besides causing oxidative damage to lipids and proteins also react with nitric oxide, produced by activated microglia, enhancing the formation of peroxynitrite and other reactive nitrogen species (RNS). In the conditions of oxidative/nitrosative stress (OS/NS), proteins are subjected to PTMs generally associated with loss of function. If the oxidized proteins are not adequately repaired or removed, toxic cell damage occurs. Protein oxidation involves modifications of three-dimensional structures and physiochemical properties that can result in fragmentation, aggregation, and increased susceptibility to 
proteolysis (Berlett \& Stadtman, 1997; Butterfield \& Lauderback, 2002; Stadtman \& Levine, 2003). Moreover, it has been shown that the increased level of oxidized protein is often associated with loss of proteasomal activity, which represents a major enzyme for the degradation of oxidized proteins (Keller et al., 2000a; Petropoulos et al., 2000; Szweda, Friguet, \& Szweda, 2002).

Common markers of OS are: protein oxidation indexed by protein carbonyls, 3-nitrotyrosine (3-NT) and protein glutathionylation (Berlett \& Stadtman, 1997; Smith et al., 1997), lipid peroxidation indexed by thiobarbituric acid-reactive substances (TBARS), free fatty acid release, iso- and neuro-prostane formation, 2-propen-1-al (acrolein), and 4-hydroxy-2-transnonenal (HNE) (Butterfield \& Lauderback, 2002), DNA oxidation (8-hydroxy-2-deoxyguanosine) (Mecocci, MacGarvey, \& Beal, 1994) and advanced glycation end products (AGEs) detection (Vitek et al., 1994) as illustrated in Figure 1. In the case of increased OS, redox proteomics analyses are broadly used as a tool to identify proteins that are modified by ROS/RNS that contribute to the development of neurodegenerative (DalleDonne et al., 2006a; Butterfield \& Sultana, 2008; Butterfield et al., 2012) and other diseases.

\section{B. Markers of Protein Oxidation}

\section{Protein Carbonylation}

Carbonylation is one of the most commonly occurring oxidative PTMs and its measurement can be a good indicator of the extent of oxidative damage of proteins associated with various conditions of OS, aging, and physiological disorders (Berlett \& Stadtman, 1997). Indeed the number of carbonyl groups observed within a protein correlates with protein damage caused by OS (Shacter et al., 1994). One-third of the total proteins are carbonylated in animals approaching full life span and it is reported that genes extending life span decrease carbonylation, while those shortening life span increase carbonylation (Sheehan, 2006). Protein carbonyl groups are generated by direct oxidation of several amino acid side chains (i.e., Lys, Arg, Pro, Thr, His, and others), backbone fragmentation, hydrogen atom abstraction at alpha carbons and Michael addition reactions of His, Lys, and Cys residues with products of lipid peroxidation causing inactivation, crosslinking, or breakdown of proteins (Butterfield \& Stadtman, 1997). The most abundant carbonyls in aged cells are 2-amino-adipic semialdehyde (AAS) and gamma-glutamyl semialdehyde (GGS) (D'Alessandro et al., 2011). Protein carbonyls are also produced by glycation/ glycoxidation of Lys amino groups, forming AGEs (Berlett \& Stadtman, 1997; Stadtman \& Berlett, 1998), and Michael adducts of $\alpha$, $\beta$-unsaturated aldehydes produced by lipid peroxidation (Sultana, Perluigi, \& Allan Butterfield, 2012).

\section{Protein-Bound 3-NT}

Protein tyrosine nitration to form 3-NT has been widely considered as a valid biomarker of protein RNS insult occurring in a variety of diseases (Yeo et al., 2008). The formation of 3-NT is one of the most studied chemical modifications and is generally considered as a marker of peroxynitrite formation and irreversible protein damage. Increased 3-NT levels have been detected in $\mathrm{AD}, \mathrm{ALS}, \mathrm{PD}$, atherosclerosis, and acute lung disease disorders (Castegna et al., 2003; Dalle-Donne et al., 2006b; Sultana et al., 2006c). 3-NT is widely assumed to arise from the reaction with peroxynitrite, which is formed by the simultaneous generation of $\mathrm{NO}$ and superoxide radicals in the presence of $\mathrm{CO}_{2}$. However, there is evidence for alternative pathways, including one mediated by myeloperoxidase shown in Figure 2 (Ghezzi \& Bonetto, 2003). The addition of nitrite to the protein tyrosine residues affects its role in redox cell signaling and oxidative inflammatory response and impedes cysteine phosphorylation, which is crucial for regulation of protein function (Schopfer, Baker, \& Freeman, 2003).

\section{Protein-Bound HNE}

Lipid peroxidation is one of the major sources of free radicalmediated injury that directly damages membranes and generates a number of secondary products. The overall process of lipid peroxidation consists of three stages: initiation, propagation and termination. The initiation involves the attack of lipid-resident free radicals to an allylic hydrogen atom on acyl chains of lipids to form a carbon-centered radical. This radical reacts with paramagnetic oxygen $\left(\mathrm{O}_{2}\right)$ to produce peroxyl radicals. These peroxyl radicals can react with adjacent allylic $\mathrm{H}$ atoms on acyl chains of lipids forming a lipid hydroperoxide and a C-centered radical, thus propagating the chain reactions. Depending on a number of factors, including acyl chain length and degree of unsaturation, the lipid hydroperoxide can decompose to produce multiple reactive products such as, malondialdehyde (MDA) and HNE that are significantly elevated in several neurodegenerative diseases (Esterbauer \& Cheeseman, 1990; Esterbauer, Schaur, \& Zollner, 1991; Subramaniam et al., 1997; Sultana \& Butterfield, 2009). HNE can accumulate in cells in relatively high concentrations and cause cell toxicity. Increased levels of HNE cause disruption of $\mathrm{Ca}^{2+}$ homeostasis, glutamate transport impairment, membrane damage, and cell death (Reed, 2011). Once formed, HNE can covalently modify cysteine, lysine, or histidine residues by Michael addition altering protein structure and causing loss of function and activity (Subramaniam et al., 1997; Markesbery \& Lovell, 1998). Several methods have been developed for detection of free HNE, its metabolites, or its conjugation products with biomolecules.

\section{Protein Glutathionylation and Other OS Markers}

Other direct or indirect commonly used markers of protein oxidation are: protein glutathionylation, protein disulfide formation, protein ubiquitinylation, $S$-nitrosylation, AGEs, and advanced oxidation protein products (AOPPs) (Witko-Sarsat et al., 1996; Munch et al., 1997; Dalle-Donne et al., 2007). Protein glutathionylation is the formation of a mixed disulfide between protein cysteinyl residues and the small-molecularweight thiol and antioxidant glutathione. The reversible glutathionylation of proteins is important in the response of cells to oxidative damage and may also be significant in redox signaling (Dalle-Donne et al., 2007). This modification occurs mainly under OS conditions but may also be important under normal conditions, especially for regeneration of several thiol peroxidases. Glutathionylation can protect cysteine thiols against irreversible oxidation but can also alter, either positively or negatively, the activity of many proteins. Therefore, glutathionylation allows cells to sense and signal harmful stress 


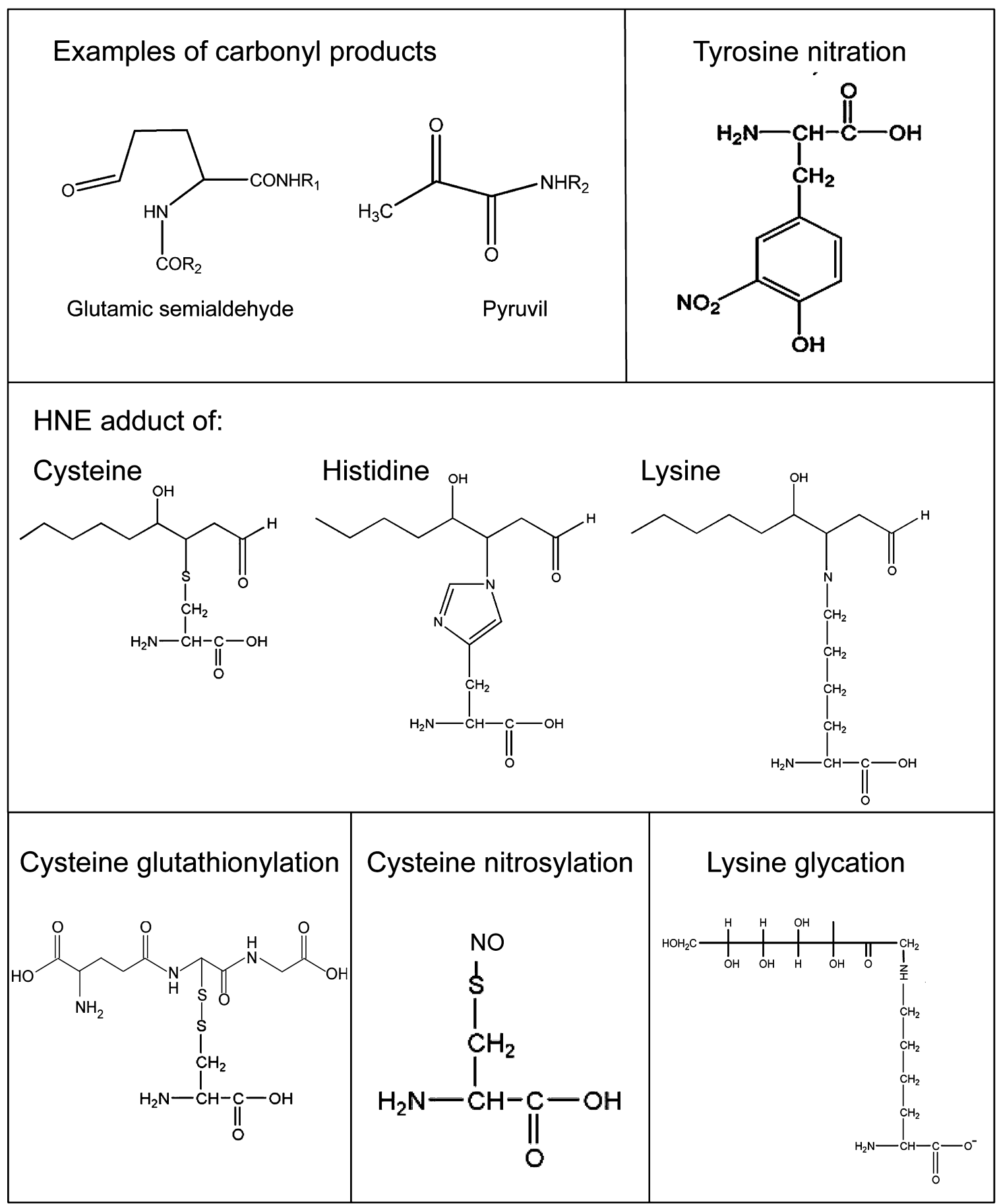

FIGURE 1. Examples of oxidative post-translational modifications.

conditions and trigger appropriate responses (Giustarini et al., 2004).

Protein disulfides are formed by the action of protein disulfide isomerase in the endoplasmic reticulum (ER). Inappropriate disulfide bridges (and cysteine sulfenic acids) arise in response to OS and are under the reversible control of the thioredoxin reductase system. Oxidatively damaged proteins have been reported as being cleared via ubiquitinylation followed by digestion in the $20 \mathrm{~S}$ core of the $26 \mathrm{~S}$ proteasome in the cytosol and nucleus (Stadtman et al., 1988; Grune, Reinheckel, \& Davies, 1997). Thus targeting ubiquitin bound to protein can be used as a parameter of protein oxidation. However, protein oxidation and ubiquitinylation might not be always directly correlated (Sheehan, 2006).

$S$-nitrosylation of protein cysteines to yield nitrosothiols is also an important mechanism of redox regulation and it is now considered a major mechanism by which NO can modulate the activity of several proteins. As well as glutathionylation also this 


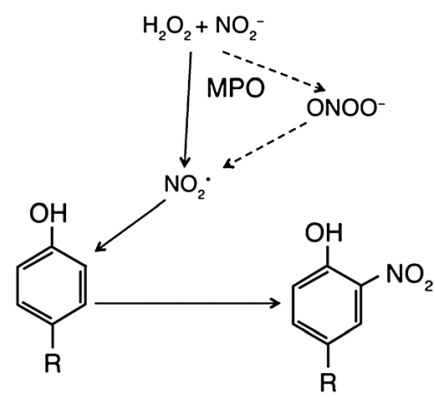

FIGURE 2. Myeloperoxidase-dependent formation of 3-nitrotyrosine.

reaction is reversible and nitrosothiols can be reduced by ascorbic acid, GSH, and thioredoxin (Ghezzi \& Bonetto, 2003).

Non-enzymatic glycosylation is a common PTM of proteins in vivo, resulting from reactions between glucose and amino groups on proteins; this process is coined the "Maillard reaction" and results in the formation of AGEs. AOPPs, a relatively novel marker of oxidative damage, are considered as reliable markers to estimate the degree of oxidant-mediated protein damage. They are formed during OS by the action of chlorinated oxidants, mainly hypochlorous acid and chloramines (produced by myeloperoxidase in activated neutrophils).

\section{REDOX PROTEOMICS: A NEW AVENUE}

Currently, the two major approaches used in redox proteomics research are gel-based and non-gel methods. A schematic overview of the general workflow in a gel-based approach is shown in Figure 3. In gel-based methods, oxidized proteins extracted from biological tissues are separated using twodimensional gel electrophoresis (2DE) separation whereby proteins migrate on a polyacrylamide gel according to their isoelectric focusing points and relative mobilities. Gels can be transferred onto a 2D Western blot and specific antibodies used to visualize oxidized spots. Oxidized spots of interest are excised from the gel and identified using a peptide mass fingerprinting (PMF) MS approach (Wittmann-Liebold, Graack, \& Pohl, 2006; Kim et al., 2007; Butterfield \& Sultana, 2008; Sheehan, McDonagh, \& Barcena, 2010; Butterfield et al., 2012) The PMF approach can be carried out with matrix-assisted laser desorption ionization (MALDI)-MS or electrospray ionization (ESI)-MS. Gel-based methods are advantageous because they target a specific subset of the proteome and numerous gels can be ran and aligned with sophisticated software tools.

Alternative approaches, which do not involve gels but rather liquid chromatography separations, and MS and tandem MS (MS/MS), have also been applied in redox proteomics as shown in Figure 4. A non-gel proteomic method includes the digestion of proteins into peptides in solution, the nanoflow LC separation of peptides and automated MS and MS/MS data acquisition.

Due to the availability of human and other species genomic databases, raw MS data, no matter the MS platform, can be searched against protein databases using searching tools such as MASCOT (Perkins et al., 1999) and SEQUEST (Eng, McCormack, \& Yates, 1994). This bottom-up approach can often identify more lowly abundant, hydrophobic, and highly acidic/ basic proteins, which are not suitable in gel separations. The automation and fast MS scan times also significantly improves the experimental throughput relative to gel-based techniques (Roe \& Griffin, 2006).

Additionally, one major aim of redox proteomics is to quantify different redox levels between two or more physiological states. Several quantification techniques, such as selective reaction monitoring (SRM), isobaric tagging (Ross et al., 2004) and ${ }^{18}$ O-labeling (Rauniyar \& Prokai, 2011) have been reported for quantifying carbonylated proteins. It should be noted that amine-reactive isobaric tags such as iTRAQ or TMT reagents and ${ }^{18} \mathrm{O}$-labeling do not react with carbonyl groups exclusively or directly. This means other chemical labeling tags can be incorporated into the redox proteomics workflow. Below we discuss an example of a recently reported tag, carbonyl-reactive tandem mass tags, reported to be useful in quantification of $\mathrm{N}$ linked glycans (Hahne et al., 2012). This hybrid tag contains an aminooxy moiety for carbonyl labeling and a TMT moiety for quantification. By using this carbonyl-reactive TMT label carbonylated proteins can be directly quantified from multiple samples.

\section{A. Gel-Based Redox Proteomic Methods}

\section{1. $2 D$ Western Blotting}

Western blotting (WB) is usually incorporated in 2D-gel based redox proteomics because immunochemical detection of oxidatively modified proteins offers high sensitivity and specificity. Antibodies are selected based on the type of oxidative modification to be studied (e.g., protein carbonyls, 4-HNE, 3-NT, and glutathionylation). 2D Western blotting is a widely used, robust, and popular approach for redox proteomics analyses. Noted limitations with the approach result from the gel electrophoresis separation, which includes co-migration of multiple proteins on gels to a single spot and bias against heavily acidic or basic and hydrophobic proteins. Redox proteomics analysis is often followed by validation experiments on the proteins identified as oxidatively modified by specific immunoprecipitation (IP) and WB analysis.

\section{a. Protein carbonyls}

One of the applications of this type of approach is protein carbonylation (Yan \& Forster, 2011; Butterfield et al., 2012). After treatment with 2,4-dinitrophenylhydrazine (DNPH) to form a DNP hydrazone adduct, protein samples can be resolved by 2D gel electrophoresis, transferred to a nitrocellulose or PVDF membrane, and recognized by anti-DNP antibodies. Protein carbonyl (PCO) derivatization can occur before or after the gel separation (Linares et al., 2011). Individual PCO signals from the blot are normalized to the total protein level present on the gel and compared across different conditions (Irazusta et al., 2010; Sheehan, McDonagh, \& Barcena, 2010). It is possible with this strategy for PCO on low abundant proteins to be detected.

Despite the extensive usage of DNPH for derivatizing PCO it should be noted that DNPH is not exclusive for carbonyl groups, as it also reacts with sulfenic acids-oxidized thiol groups-under acid catalysis conditions (Dalle-Donne et al., 2009). Biotin-hydrazide may be used to label carbonyl groups with fluorescein or peroxidase linked avidin (Oh-Ishi, 


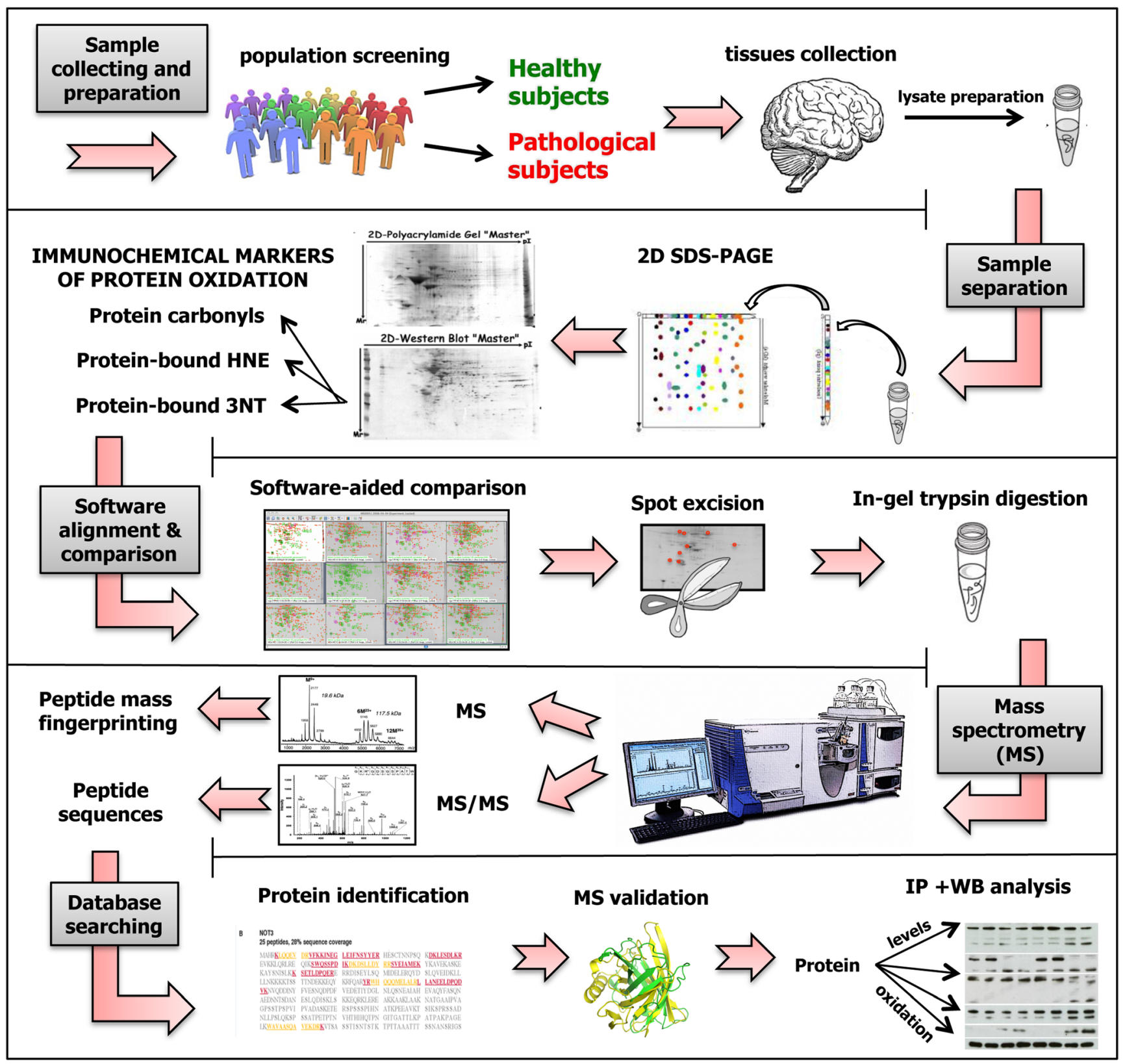

FIGURE 3. Schematic overview of gel-based redox proteomics approaches.

Ueno, \& Maeda, 2003; Yoo \& Regnier, 2004). A protein carbonyl enzyme immuno-assay kit has recently become available (Korolainen \& Pirttila, 2009).

With DNPH derivatization of PCO groups, the number of modification sites identified is limited with ESI-MS (Nagy et al., 2004). This could be attributed to low ESI efficiency of DNPH derivatized peptides on positive mode. The two nitro groups present on the benzene ring of DNPH have a strong electron withdrawing effect which may diminish the stability of the protonated peptide. Detection of nanomolar range of aldehyde-DNPH derivatives can be achieved by negative mode of atmospheric pressure chemical ionization (APCI) (Andreoli et al., 2003; Korchazhkina, Exley, \& Andrew Spencer, 2003). More favorable ionization behaviors of DNPH-labeled carbony- lated peptides arise in negative ion mode ESI (Bollineni, Fedorova, \& Hoffmann, 2011) which provides the advantage of the DNPH moiety being useful for readily identifying the PCO site (Bollineni, Fedorova, \& Hoffmann, 2011).

b. 3-NT, HNE, glutathionylation, and other oxidatively-modified proteins

Similarly, the 2D gel-based strategy can be applied to other oxidative modifications, such as 4-HNE, 3-NT, and glutathionylation whereby the derivatization steps are not necessary. Thus, an advantage of gel-based redox proteomics is the broad applicability to numerous modifications only limited by antibody availability. Antibodies provide high selectivity and sensitivity for oxidized protein identification (Kurien 


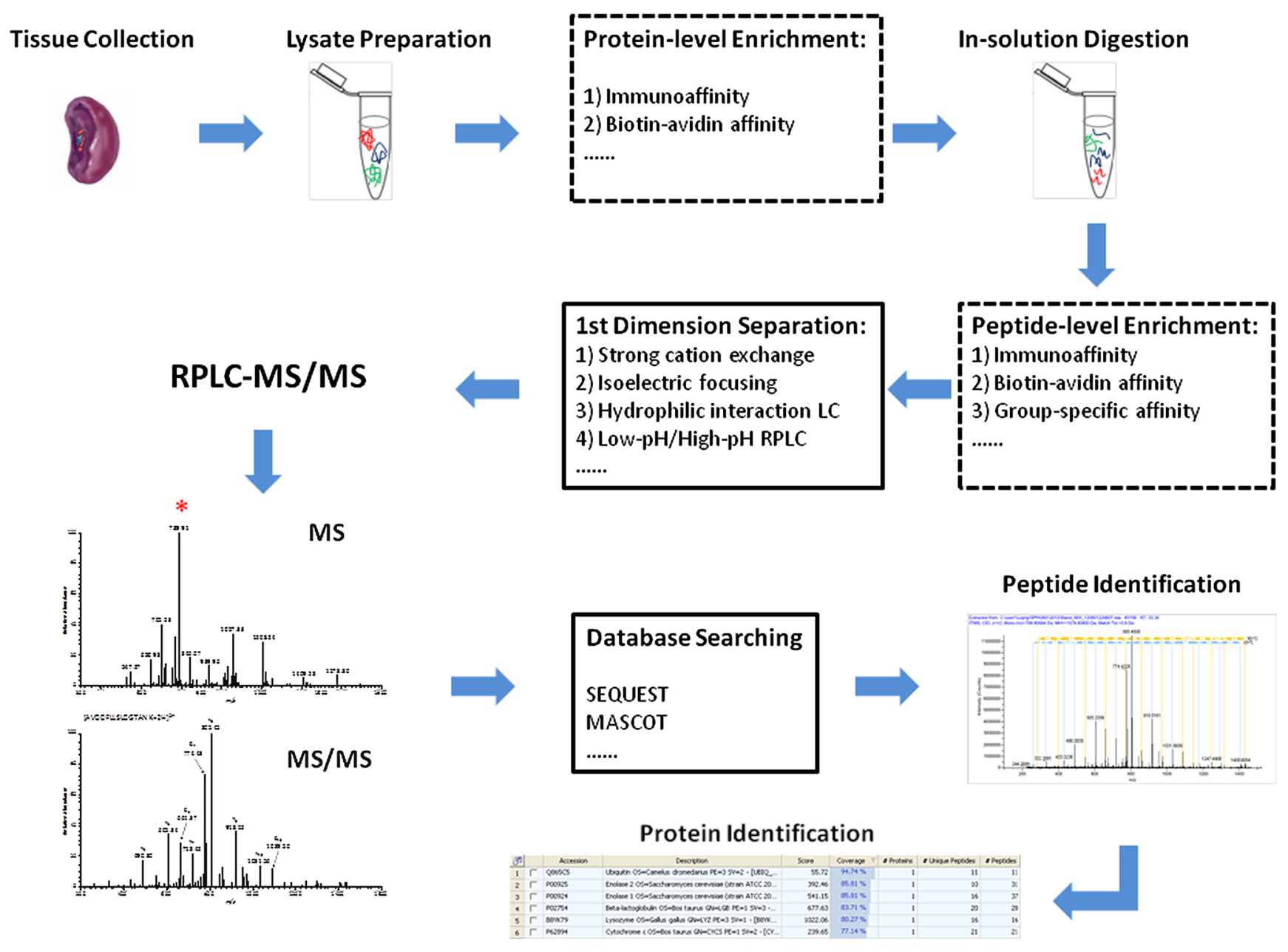

FIGURE 4. Schematic overview of non-gel based shotgun redox proteomics approaches.

et al., 2011). 3-NT is a relatively stable modification, thus it can be suitably analyzed by immunochemical detection with anti-3NT specific antibodies (Soderling et al., 2003; Sultana et al., 2006c). Free HNE can be quantified by HPLC, however, due to the relative instability of HNE, the determination of biological adducts is preferred. In recent years analytical possibilities have been greatly expanded because of the availability of polyclonal and monoclonal antibodies directed against protein-bound cysteine, lysine or histidine adducts of HNE (Perluigi et al., 2009). Rapid and simple kits with monoclonal antibodies are already commercially available. Although MDA and HNE represent the major products of lipid peroxidation, other aldehyde products, including acrolein and isoprostanes, are formed. Like other lipid peroxidation products, isoprostanes and neuroprostanes can be used as markers of OS and are being investigated as prospective biomarkers for disease (Reed, 2011).

Considering the potential importance of glutathionylation, a number of methods have been developed for identifying proteins undergoing this modification. Protein glutathionylation can be either visualized and quantitated using radiolabeled GSH detected by fluorography, or analyzed with immunochemical methods that exploit monoclonal antibody anti-GSH bounded to the proteins (Newman et al., 2007; Gao et al., 2009). Commercially available antibodies to ubiquitin and polyubiquitin facili- tate identification of ubiquitinylated proteins in blots of 2D SDS-PAGE separations. The detection methods for $S$-nitrosylated proteins (PSNO) in gel electrophoresis are conceptually similar to that developed to detect glutathionylated proteins. Free thiol groups $(\mathrm{SH})$ are blocked with a reagent that does not react with nitrosothiols, then the nitrosothiols are reduced to thiols with ascorbate and the $\mathrm{SH}$ thus produced are derivatized with a biotinylated thiol reagent so that derivatized proteins can then be identified by immunoblotting and/or immunoaffinity (Jaffrey et al., 2001). Anti-SNO antibodies have been recently developed and can be used in proteomics approaches.

Measurement of AGEs can be performed or by competitive ELISA kit or by quantitative fluorescence spectroscopy (Munch et al., 1997). ELISA kit uses either a monoclonal antibody directed against imidazolone, an AGE formed by reaction of arginine with 3-deoxyglucosone, or a polyclonal antibody against hemocyanin-AGE. Determination of AOPPs in plasma is based on spectrophotometric detection, according to method proposed by Witko-Sarsat et al. (1996).

\section{2. $2 D-D I G E$}

Two-dimensional difference gel electrophoresis (2D-DIGE) has been widely applied in gel-based redox proteomics. This method 
uses fluorescent dyes (e.g., Cy2, Cy3, and Cy5) to covalently label protein samples, allowing two to three samples to be analyzed simultaneously on the same gel in which signals are scanned at different wavelengths (Unlu, Morgan, \& Minden, 1997). The common labeled residues are cysteine and lysine with functional NHS-ester and maleimides dyes, respectively. Incorporation of multiple dye molecules into protein sequence may change its migration significantly therefore minimal labeling has been developed to address this issue (Gharbi et al., 2002). 2D-DIGE technique addresses the limitations of lack of reproducibility between gels and has femptomolar sensitivity and a $10^{4}$ dynamic range (Timms \& Cramer, 2008).

The $\mathrm{Cu}^{1+}$-catalyzed azide-alkyne $[3+2]$ cycloaddition (CuAAC) reaction, known as "click chemistry," is a useful coupling technology for the conjugation of biomolecules, for example, DNA, proteins, glycans and lipids (Lallana, Riguera, $\&$ Fernandez-Megia, 2011). Some attractive merits of this protocol are as follows: (1) there are no azides and alkynes in native biomolecules, making this method highly selective; (2) click chemistry can take place in aqueous solution without significant cytotoxic effects, so it is a biological compatible reaction; (3) the combination of probe and reporter tag is flexible, so various types of molecules, including dyes, can be incorporated into this reaction (Amblard, Cho, \& Schinazi, 2009; Hang, Wilson, \& Charron, 2011).

Click chemistry has been applied in redox proteomics in a recent novel 2D-DIGE report on the study of the nascent proteome (Osterman et al., 2012). The methionine analogue, homopropargylglycin (HPG), selectively reacts with the azide group on the Cys3 and Cys5 through CuAAC reaction, making new proteins detectable. Another major application of click chemistry in redox proteomics is in the study of protein modification by electrophiles, specifically, HNE (Vila et al., 2008; Kim et al., 2009; Jacobs \& Marnett, 2010; Codreanu et al., 2012). Click chemistry overcomes some of the limitations of biotin hydrazide/affinity chromatography by its specific reaction between azide and alkyne groups which makes the approach specific for the detection of HNE, as opposed to other carbonyl groups. While there are few reports of click chemistry being used for other modifications in redox proteomics, it may offer an alternative approach to study other oxidative PTMs (e.g., side chain carbonylation, 3NT, and thiol redox).

\section{B. Non-Gel Based Redox Proteomics}

\section{Protein Carbonyls}

Non-gel redox proteomics have been widely applied in the study of protein carbonylation and have been reviewed recently (Madian \& Regnier, 2010a; Yan \& Forster, 2011; Butterfield et al., 2012). A key step in these approaches is the incorporation of enrichment procedures for PCO which is necessary since the average abundance of carbonylated proteins has been reported as $\sim 0.2 \%$ in human plasma (Madian \& Regnier, 2010b). Through elimination of the majority of unmodified proteins the chemical interference in the LC and MS dimensions can be minimized and increase the identification of PCO modified proteins.

One of the most common methods uses avidin affinity chromatography to enrich biotin-hydrazide derivatized carbony- lated peptides and proteins. Derivatization with biotin hydrazide also results in the formation of a Schiff base that can be reduced to a more stable $\mathrm{C}-\mathrm{N}$ bond. Label-free or isobaric tagging strategies (e.g., iTRAQ) can be used for quantifying carbonylation level across different samples (Madian et al., 2011a,b). Regnier and co-workers have successfully applied biotin/avidin affinity chromatography proteomics to study PCOs in in vitro metal-catalyzed oxidation models, yeast, rat and human plasma tissues, and diabetic rats (Mirzaei \& Regnier, 2005; Mirzaei et al., 2008; Madian \& Regnier, 2010a,b; Madian et al., 2011a,b).

A similar tag based on biotin/avidin is $N^{\prime}$-aminooxymethylcarbonylhydrazino D-biotin (aldehyde reactive probe, ARP), the hydroxylamine moiety of which can form a stable $\mathrm{C}-\mathrm{N}$ bond, thus further reduction is not necessary (Slade et al., 2010; Chavez et al., 2006; Chavez, Bisson, \& Maier, 2010). This ARP however undergoes substantial fragmentation in MS/MS experiments which decreases peptide confidence after database searching due to complex spectra. The development of an algorithm which incorporates ARP fragment ions and neutral loss into the database searching has enhanced PCO identification with ARPs.

In addition to biotin/avidin based approaches other enrichment reagents such as Girard's $\mathrm{P}$ and Oxidationspecific Element-Coded Affinity Tags for PCO have been previously reported and reviewed (Madian \& Regnier, 2010a). Some reagents are able to directly increase the ionization efficiency of PCO prior to MS analysis. An example is dansylhydrazide which enhances efficiency of ionization due to its secondary nitrogens. Dansylhydrazide generates reproducible fragmentation patterns which allows $\mathrm{MS}^{3}$ scans to be employed for localization of PCO sites in proteins (Palmese et al., 2011).

\section{4-HNE}

4-Hydroxy-2-trans-nonenal (HNE) modified proteins or peptides can be isolated using solid-phase hydrazide (SPH) beads (Roe et al., 2007; Rauniyar, Prokai-Tatrai, \& Prokai, 2010; Rauniyar \& Prokai, 2011). SPH reagent has a hydrazide group, which can react with active carbonyl groups and form a hydrazone bond. After centrifuge separation, bound protein or peptides can be extracted from complex samples. The hydrazone bond is reversible and can be hydrolyzed in acidic aqueous solution. One advantage of this method is that after hydrolysis, the carbonyl groups remain intact making it possible for further labeling, identification, or quantification.

\section{Protein Nitration}

Biotin/avidin is also widely used to enrich 3-NT proteins or peptides (Abello et al., 2010). To label with biotin tags, primary amino groups of nitrated peptides should be blocked, prior to 3NT reduction to 3-aminotyrosine. Amine-reactive biotin tags are then incubated with 3-NT reduced peptides and enriched with avidin chromatography. This general strategy can employ different blocking reagents and biotin-based tags, making it a flexible method in protein nitration identification. Additionally, to quantify 3-NT-modified proteins, the incorporation of iTRAQ labels has been reported (Chiappetta et al., 2009). Recently, Robinson and Evans presented a novel strategy, combined precursor and isotopic labeling (cPILOT) which increases 
multiplexing capabilities to up to 16 samples with iTRAQ reagents (Robinson \& Evans, 2012). cPILOT uses "light" and "heavy" labeled acetyl groups to label primary amine groups and iTRAQ or tandem mass tag (TMT) reagents to label reduced 3-NT residues.

\section{Sulfur Redox Considerations}

While some oxidative modifications are largely irreversible, oxidation of cysteine SH groups (e.g., formation of cysteine sulfenic acid, disulfides, glutathionylation) are reversible, which makes it challenging to follow cysteine redox status. Typically, two steps are needed for analyzing the thiol proteome: blocking free thiols and reducing reversibly oxidized thiols (Sheehan, McDonagh, \& Barcena, 2010). Different reductants have different selectivity, so specific forms of oxidation can be characterized. Additionally, a stable isotope labeling (SIL) technique has been introduced to quantify oxidized cysteine sites (Ying et al., 2007). Recently, a novel gel-based strategy for global analysis of the dynamic thiol redox proteome was developed to quantitatively reveal the changes in both cysteine redox state and in protein abundance (Martinez-Acedo et al., 2012). Cysteine alkylated proteins were separated by SDS-PAGE and following in-gel digestion were further reduced and alkylated with a different reagent. After in-gel digestion and differential ${ }^{16} \mathrm{O} /{ }^{18} \mathrm{O}$ labeling, samples are subjected to LC-MS/MS analysis. Quantification of relative protein abundance across different physical conditions can be achieved by non-cysteine-containing peptides, while cysteine-containing peptides are used for quantifying unmodified and oxidized cysteine residues. This gel-based strategy provides an alternative method for quantifying global protein expression and examining cysteine oxidation simultaneously.

Additionally, purification of reversibly oxidized proteins (PROP) utilizing $N$-ethylmaleimide (NEM) to block unmodified thiol groups and reduce oxidized thiols to generate new free thiols has recently been reported (Victor et al., 2012). A commercially available thiol reactive bead which contains a 2pyridyl disulfide group can be used to react with newly formed thiols and isolate oxidized proteins. After isolation, the bead-SS-protein disulfide bond can be reduced by dithiothreitol which can be labeled with iodoacetamide. Different blocking reagents can be differentiated by MS, so unmodified and oxidized cysteines can be identified simultaneously. To quantify the level of the thiol modifications under oxidative stress conditions, thiol trapping techniques and isotope coded affinity tag (ICAT) can be combined to label unmodified and oxidized thiol groups with light and heavy tags, respectively (Lindemann \& Leichert, 2012). This method named NOxICAT is specific for nitrosative and oxidative modifications of thiol groups. After protein denaturation, free thiol groups are labeled with light ICAT reagents. Oxidized thiols are labeled with heavy ICAT reagents and the extent of cysteine oxidation is measured by quantifying the relative ratios of light and heavy labeled peptides with MS.

Difference gel electrophoresis (DIGE) and ICAT were compared as redox proteomics methods for the analysis of mouse heart tissue treated with hydrogen peroxide (Fu et al., 2008). The results showed the two methods were largely complementary, since both of them could reveal unique redox- sensitive proteins. Combining gel and non-gel based redox proteomics could be helpful for better characterizing redox status.

\section{APPLICATIONS OF REDOX PROTEOMICS}

\section{A. Diseases}

Redox proteomics has been used as a tool to understand many diseases and neurodegenerative disorders. The diseases and neurodegenerative disorders highlighted in this review are listed in Tables 1 and 2, respectively.

\section{Kidney Disease (KD)}

The important physiological functions of kidney include removing waste materials, balancing water, electrolyte and physiological buffer systems, and reabsorbing useful components (Thongboonkerd \& Malasit, 2005). Blood flow and oxygenation in the kidney varies from the well-perfused cortex to near-anoxic medulla. The imbalance of redox homeostasis in kidney tissue may result in changes of proteome expression and oxidative PTMs. Oxidative stress is implicated in kidney-related pathologies, from chronic kidney disease (CKD) to end-stage kidney disease. The study of proteome, including the protein oxidative PTMs, are of importance to reveal the relative biomarkers and diagnose the disease at the early stage.

The various techniques of protein oxidative PTMs characterization, from gel-based method to shotgun approach, have been widely applied to study the proteome of kidney disease. In a relative early study on kidney disease patients undergoing hemodialysis, tyrosine nitration level of plasma proteins was shown to increase significantly in comparison with controls (Mitrogianni et al., 2004). Immunoprecipitation followed by western blot was used to identify nitrated proteins and indicated ceruloplasmin as one of the proteins having significant nitration. Kidney dsyfunction interferes with redox balance resulting in high levels of oxidative PTMs. Redox proteomics studies of renal medulla of spontaneous hypertensive rats has identified 19 nitrated proteins (Tyther et al., 2007). Another kidney disease-related study was performed to examine the plasma nitroproteome of chronic kidney disease and end-stage KD patients (Piroddi et al., 2011). Proteins of chronic and end-stage KD patients had a higher nitration level than in healthy controls and uremic albumin is largely represented in the uremic nitroproteome by immunoblotting experiment.

Cysteine oxidation has also been examined in kidney disease. In the study of protein sulfenation in renal medulla of the spontaneous hypertensive rat (SHR) (Tyther et al., 2010), total free thiol content was significant lower than controls. The decrease of thioredoxin reductase activity may contribute to enhanced protein sulfenation. Several proteins bearing sulfonation were identified with gel-based redox proteomics. Additionally, different oxidative PTMs may show correlation with the level of disease. In a study of plasma protein thiol oxidation and carbonylation of CKD patients (Matsuyama et al., 2009), both reversibly oxidized human serum albumin (HSA) and irreversibly oxidized albumin (HAS) content increased with a decrease in renal function. The relation between different oxidative 
TABLE 1. Applications of redox proteomics in the study of human non-neurodegenerative diseases

\begin{tabular}{|c|c|c|c|}
\hline Disease Pathology & Tissue & Oxidative modification & References \\
\hline Cancer & $\begin{array}{l}\text { Peripheral blood } \\
\text { mononuclear cells } \\
(\text { PBMCs })\end{array}$ & Lipid peroxidation & $\begin{array}{c}\text { (Haudek, Gundacker et } \\
\text { al. 2008) }\end{array}$ \\
\hline Cancer & Skin fibroblast & Cysteine oxidation & (Wu, Chou et al. 2012) \\
\hline Cancer & Rat tumor tissue & $\begin{array}{c}\text { Carbonylation and lipid } \\
\text { peroxidation }\end{array}$ & $\begin{array}{c}\text { (Marin-Corral, Fontes et } \\
\text { al. 2010) }\end{array}$ \\
\hline Cancer & A431 tumor cells & $\begin{array}{l}\text { Carbonylation and } \\
\text { cysteine oxidation }\end{array}$ & (Tsaytler, M et al. 2008) \\
\hline Cancer & HK-168 cells & Carbonylation & $\begin{array}{c}\text { (Perluigi, Giorgi et al. } \\
\text { 2009) }\end{array}$ \\
\hline Cardiac disease & Mouse heart tissue & ROS and RNS & $\begin{array}{c}\text { (Barjaktarovic, Schmaltz } \\
\text { et al. 2011) }\end{array}$ \\
\hline Cardiac disease & Mouse heart tissue & $3 \mathrm{NT}$ & $\begin{array}{c}\text { (Kanski, Behring et al. } \\
\text { 2005) }\end{array}$ \\
\hline Diabetes & Blood & S-Glutathionylation & (Niwa, Naito et al. 2000) \\
\hline Diabetes & Rat plasma & Carbonylation & $\begin{array}{l}\text { (Madian, Myracle et al. } \\
\text { 2011) }\end{array}$ \\
\hline Diabetes & Human plasma & $3 \mathrm{NT}$ & $\begin{array}{l}\text { (Hoeldtke, Bryner et al. } \\
\text { 2002) }\end{array}$ \\
\hline Diabetes & $\begin{array}{l}\text { SERCA2a from } \\
\text { membrane vesicles }\end{array}$ & Carbonylation & (Shao, Capek et al. 2011) \\
\hline Heart failure & Ventricular tissue & Carbonylation & $\begin{array}{l}\text { (Brioschi, Polvani et al. } \\
\text { 2012) }\end{array}$ \\
\hline Hypertension & Mouse medulla proteins & $\begin{array}{l}\text { Carbonylation, cysteine } \\
\text { oxidation }\end{array}$ & $\begin{array}{l}\text { (Tyther, Ahmeda et al. } \\
\text { 2009) (Tyther, Ahmeda } \\
\text { et al. 2010) }\end{array}$ \\
\hline $\begin{array}{l}\text { Ischemia Reperfusion } \\
\text { (IR) Injury }\end{array}$ & Liver cytosolic extracts & Cysteine oxidation & $\begin{array}{l}\text { (Wilson, Zeile et al. } \\
\text { 2011) }\end{array}$ \\
\hline $\begin{array}{l}\text { Ischemia Reperfusion } \\
\text { (IR) Injury }\end{array}$ & Mouse heart tissue & $\begin{array}{l}\text { Cysteine nitrosylation } \\
\text { and oxidation }\end{array}$ & (Kohr, Sun et al. 2011) \\
\hline Kidney Disease & Plasma Proteins & $3 \mathrm{NT}$ & $\begin{array}{c}\text { (Mitrogianni, Barbouti et } \\
\text { al. 2004) }\end{array}$ \\
\hline Kidney Disease & Mouse medulla proteins & $3 \mathrm{NT}$ & $\begin{array}{l}\text { (Tyther, Ahmeda et al. } \\
\text { 2007) }\end{array}$ \\
\hline Kidney Disease & Human Blood & $3 \mathrm{NT}$ & $\begin{array}{l}\text { (Piroddi, Palmese et al. } \\
\text { 2011) }\end{array}$ \\
\hline Kidney Disease & Human Blood & $\begin{array}{l}\text { Cysteine oxidation and } \\
\text { carbonylation }\end{array}$ & $\begin{array}{l}\text { (Matsuyama, Terawaki et } \\
\text { al. 2009) }\end{array}$ \\
\hline
\end{tabular}

stresses and disease may contribute to development of early diagnostic technique of diseases.

\section{Ischemia Reperfusion (IR) Injury}

Surgical treatment, for example, organ section or transplantation, may contribute to ischemia reperfusion (IR) injury (Oliver et al., 1990). The sudden increase of ROS in the first few minutes of reperfusion following ischemia results in the imbalance of redox potential in tissue, ending with protein oxidative PTMs, especially thiol oxidation. 2D-DIGE was used to identify cytosolic protein changes in the early phase of rat liver IR injury. Peroxiredoxins 1 (Prx1) had a threefold increase, which indicated the reduced protective effect of Prx1 upon ROS. Additionally, overoxidation of $\mathrm{Cys}^{173}$ of Prx1 was identified (Wilson et al., 2011). Recently, a study on simultaneous measurement of protein oxidation and $S$-nitrosylation was reported (Kohr et al., 2011). IR injury can generate two types of thiol oxidation products, thiol oxidation and $S$-nitrosylation. Because they have different redox activities, simultaneous measurement of these two proteins is not easy to perform. This report used two different parallel methods to selectively block free thiols and reduce modified thiols, and enriched thiol peptides by resinassisted capture (RAC). Label-free peptide quantification demonstrated the increased $S$-nitrosylation and decreased oxidation at the same residue, indicating the protective effect of SNO against cysteine oxidation upon IR injury.

\section{Cardiac Pathology}

In the cardiovascular system, redox signaling regulates many physiological events, for example, excitation-contraction coupling. We refer the reader to a recent review on this topic (Kumar et al., 2012). NADPH oxidase generates large amounts of ROS, and the resulting ROS further converts into $\mathrm{HOCl}$ by myeloperoxidase, triggers "oxidative burst" and forms reactive nitrogen 
TABLE 2. Redox proteomic studies of neurodegenerative diseases

\begin{tabular}{|c|c|c|c|c|c|}
\hline Pathology & Sample & $\begin{array}{l}\text { Oxidative } \\
\text { modification }\end{array}$ & Oxidatively modified proteins & $\begin{array}{l}\text { Altered biological } \\
\text { functions }\end{array}$ & References \\
\hline \multirow[t]{9}{*}{ AD } & \multirow[t]{4}{*}{$\begin{array}{l}\text { Human brain } \\
\text { (hippocampus, } \\
\text { IPL and } \\
\text { cortex) }\end{array}$} & carbonylation & $\begin{array}{l}\text { CKBB, GS, UCH-L1, DRP-2, } \\
\text { ENO1, HSC71, Pin1, PGM1, TPI, } \\
\gamma \text {-SNAP, CA, MDH, GDH, 14-3-3 } \\
\varsigma / \delta, \text { FBA A/C }\end{array}$ & $\begin{array}{l}\text { energy metabolism, protein } \\
\text { degradation, neuron } \\
\text { outgrow, cell signaling, cell } \\
\text { cycle, neurotransmission, } \\
\text { protein transport, molecular } \\
\text { chaperone }\end{array}$ & $\begin{array}{l}\text { Castegna et al. 2002a, } \\
\text { Castegna et al. 2002b, } \\
\text { Sultana et al. 2006a,b, } \\
\text { Korolainen et al. } 2006 \text {. }\end{array}$ \\
\hline & & nitration & $\begin{array}{l}\text { ENO1, LDH, neuropolypeptide h3, } \\
\text { TPI, } \beta \text {-actin, GAPDH, ATP } \\
\text { synthase } \beta \text {-chain, CAII, VDAC }\end{array}$ & $\begin{array}{l}\text { energy metabolism, cell } \\
\text { structure, cell signaling, } \\
\text { mitochondrial transport, }\end{array}$ & $\begin{array}{l}\text { Castegna et al. } \\
2003 \text {, Sultana et al. } 2006 \mathrm{c} .\end{array}$ \\
\hline & & HNE-bound & $\begin{array}{l}\text { ATP synthase, GS, MnSOD, DRP- } \\
2 \text {, ENO1, Aco, ALDO, PRX6, } \alpha- \\
\text { tubulin }\end{array}$ & $\begin{array}{l}\text { energy metabolism, } \\
\text { antioxidant, neuron } \\
\text { outgrow, cell structure }\end{array}$ & Perluigi et al. 2009a \\
\hline & & glutathionylation & $\begin{array}{l}\text { deoxyhemoglobin, } \alpha \text {-crystallin B, } \\
\text { GAPDH, ENO1 }\end{array}$ & $\begin{array}{l}\text { energy metabolism, oxygen } \\
\text { transport, molecular } \\
\text { chaperone }\end{array}$ & Newman et al. 2007 \\
\hline & $\begin{array}{l}\text { Human body } \\
\text { (CSF and } \\
\text { plasma) }\end{array}$ & carbonylation & $\begin{array}{l}\lambda \text {-chain precursor, hemopexin, } \\
\text { transferrin, fibrinogen } \gamma \text { chain } \\
\text { precursor, } \alpha 1 \text { antitrypsin precursor, } \\
\text { Hp } \beta \text { chain, } \alpha 2 \text { macroglobulin }\end{array}$ & $\begin{array}{l}\text { heme transport, iron } \\
\text { transport, blood } \\
\text { coagulation, extracellular } \\
\text { chaperone, }\end{array}$ & $\begin{array}{l}\text { Korolainen et al. 2007, Yu } \\
\text { et al. 2003, Choi et al. } \\
\text { 2002, Cocciolo et al. } 2012 \text {. }\end{array}$ \\
\hline & $\begin{array}{l}\text { J } 20 \text { mouse } \\
\text { model }\end{array}$ & nitration & PEBP-1, Pin1 & Proteostasis, cell signaling & Robinson et al. 2011 \\
\hline & $\begin{array}{l}\text { synaptosomes } \\
\text { with } A \beta(1-42)\end{array}$ & carbonylation & $\begin{array}{l}\beta \text { - and } \gamma \text {-actin, GFAP, ATP } \\
\text { synthase, SNBP1, GDH, GS, } \\
\text { EAAT2, DRP-2, EF-Tu. }\end{array}$ & $\begin{array}{l}\text { cell structure, energy } \\
\text { metabolism, } \\
\text { neurotransmission, neuron } \\
\text { outgrow, protein } \\
\text { biosynthesis }\end{array}$ & Boyd-Kimball et al. 2005a \\
\hline & $\begin{array}{l}\text { rat brain with } \\
A \beta(1-42)\end{array}$ & carbonylation & $\begin{array}{l}\text { GS, tubulin } \beta \text { chain } 15 / \alpha, 14-3-3 \zeta \text {, } \\
\text { HSP } 60, \beta \text {-synuclein, PDH, } \\
\text { GAPDH, PGM1 }\end{array}$ & $\begin{array}{l}\text { Neurotransmission, cell } \\
\text { structure, cell signaling, } \\
\text { molecular chaperone, } \\
\text { energy metabolism }\end{array}$ & $\begin{array}{l}\text { Boyd-Kimball et al } \\
.2005 \mathrm{~b} \text {. }\end{array}$ \\
\hline & $\begin{array}{l}\text { C. elegans } \\
\text { with } A \beta(1-42)\end{array}$ & carbonylation & $\begin{array}{l}\text { medium and short-chain acyl-CoA } \\
\text { DH, EF-1 } \gamma, \text { MDH, AK, RACK1, } \\
\text { mlc- } 1 \text { and } 2 \text {, actin, ADK, } \\
\text { nematode specific protein, lbp- } 6 \text {, } \\
\text { TKT, } \alpha \text { and } \beta \text { proteasome subunit, } \\
\text { GST }\end{array}$ & $\begin{array}{l}\text { energy metabolism, protein } \\
\text { biosynthesis, energy } \\
\text { metabolism, protein } \\
\text { degradation, axon } \\
\text { extension, cell structure, } \\
\text { cell cycle, antioxidant }\end{array}$ & Boyd-Kimball et al. 2006. \\
\hline \multirow[t]{3}{*}{$\begin{array}{l}\text { PCAD, } \\
\text { MCI and } \\
\text { EAD }\end{array}$} & \multirow[t]{3}{*}{$\begin{array}{l}\text { Human brain } \\
\text { (hippocampus } \\
\text { and IPL) }\end{array}$} & carbonylation & $\begin{array}{l}\text { ENO1, GS, PK-M2, Pin1, CAII, } \\
\text { SBP1, MAPKI, PGM1,FBA-C, } \\
\text { GFAP, HSP90 }\end{array}$ & $\begin{array}{l}\text { energy metabolism, } \\
\text { neurotransmission, cell } \\
\text { cycle, cell signaling, neuron } \\
\text { structure, molecular } \\
\text { chaperone }\end{array}$ & $\begin{array}{l}\text { Butterfield et al. } 2006 \text { c, } \\
\text { Sultana et al. } 2010 \text {, Aluise } \\
\text { et al. } 2011 .\end{array}$ \\
\hline & & nitration & $\begin{array}{l}\text { MDH, ENO1, GRP precursor, } \\
\text { ALDO, GST, MRP3, 14-3-3 } \gamma \\
\text { PRX 6, DRP-2, fascin 1, HSP A8, } \\
\text { PRX2, TPI, GDH, } \\
\text { neuropolypeptide h3, PGM1, H- } \\
\text { ATPase, }\end{array}$ & $\begin{array}{l}\text { energy metabolism, } \\
\text { antioxidant, cell signaling, } \\
\text { neuron outgrow, molecular } \\
\text { chaperone, } \\
\text { neurotransmission, cell } \\
\text { structure }\end{array}$ & $\begin{array}{l}\text { Sultana et al. } 2007 \text {, Reed } \\
\text { et al. } 2009 \text { a }\end{array}$ \\
\hline & & HNE-bound & $\begin{array}{l}\text { LDH B, PGK, HSP } 70, \text { ATP } \\
\text { synthase, PK, } \beta \text {-actin, EF-Tu, } \\
\text { TIF } \alpha, \text { MnSOD, DRP } 2, \text { ENO1, } \\
\text { MDH, TPI, F1 ATPase } \alpha \text { subunit }\end{array}$ & $\begin{array}{l}\text { energy metabolism, cell } \\
\text { signaling, molecular } \\
\text { chaperone, cell structure, } \\
\text { protein biosynthesis, } \\
\text { antioxidant, neuron outgrow }\end{array}$ & $\begin{array}{l}\text { Perluigi et al. } 2009 b \text {, Reed } \\
\text { et al. } 2009 \text { b. }\end{array}$ \\
\hline
\end{tabular}


TABLE 2. (Continued)

\begin{tabular}{|c|c|c|c|c|c|}
\hline Pathology & Sample & $\begin{array}{l}\text { Oxidative } \\
\text { modification }\end{array}$ & Oxidatively modified proteins & $\begin{array}{l}\text { Altered biological } \\
\text { functions }\end{array}$ & References \\
\hline \multirow[t]{4}{*}{ Aging } & $\begin{array}{l}\text { SAMP8 mouse } \\
\text { model }\end{array}$ & carbonylation & LDH-2, DRP2, $\alpha$-spectrin, CK & $\begin{array}{l}\text { energy metabolism, neuron } \\
\text { outgrow, cytoskeleton } \\
\text { structure }\end{array}$ & Poon et al. 2004a \\
\hline & $\begin{array}{l}\text { Aged rats } \\
\text { hippocampus }\end{array}$ & carbonylation & $\begin{array}{l}\text { HSP 90, Cytochrome b-c1, CKB, } \\
\text { MDH, ENO1, DRP2, GS, GDH, } \\
\text { PK M1/M2 FBA-C, ATP synthase }\end{array}$ & $\begin{array}{l}\text { energy metabolism, neuron } \\
\text { outgrow, neurotransmission }\end{array}$ & Perluigi et al. 2010 \\
\hline & Aged rats cortex & carbonylation & $\begin{array}{l}\text { Prdx } 2, \cdot \text { GNBP beta- } 1, \cdot \text { CK B, } \\
\text { V-ATP-B, HSP70, Ser/thr-PP-2B, } \\
\text { ADH, } \alpha \text {-centractin, } \cdot \text { TPI, } \\
\text { GAPDH, } \cdot \text { AAT, } \cdot \text { PK M1/M2, } \\
\text { • ATP syn, FBA-A }\end{array}$ & $\begin{array}{l}\text { antioxidant, energy } \\
\text { metabolism, molecular } \\
\text { chaperone, cell signaling, }\end{array}$ & Perluigi et al. 2010 \\
\hline & $\begin{array}{l}\text { Aged rats } \\
\text { cerebellum }\end{array}$ & carbonylation & $\begin{array}{l}\text { HSC71, • } \alpha \text {-Tubulin, MDH, IDH, } \\
\text { V-ATPase, } \cdot \text { PK M1/M2, · Syn- } 2 \text {, } \\
\text { •AAT, PGK1 VDAC, AK }\end{array}$ & $\begin{array}{l}\text { cell structure, energy } \\
\text { metabolism, molecular } \\
\text { chaperone, }\end{array}$ & Perluigi et al. 2010 \\
\hline \multirow[t]{2}{*}{ PD } & $\begin{array}{l}\text { A30P } \\
\text { mutation } \\
\text { mouse model }\end{array}$ & carbonylation & CA-II, ENO1, LDH2 & energy metabolism, & Poon et al. 2005b. \\
\hline & $\begin{array}{l}\text { Rat brain } \\
\text { exposed to } \\
\text { Dopamine } \\
\text { Quinone }\end{array}$ & expression & $\begin{array}{l}\text { Gpd2, GRP75, mitofilin, NADH } \\
\text { deh.75kDa, succinate-CoA ligase, } \\
\text { IDH 3- } \alpha \text {, EF-Tu, PC, ODH, } \\
\text { MtCK, ADH, VDAC2, FAH, } \\
\text { MnSOD }\end{array}$ & $\begin{array}{l}\text { Energy metabolism, } \\
\text { molecular chaperone, } \\
\text { mitochondrial structure, } \\
\text { antioxidant, protein } \\
\text { biosynthesis. }\end{array}$ & Van Laar et al. 2008 \\
\hline \multirow[t]{2}{*}{ HD } & Human brain & carbonylation & $\begin{array}{l}\text { GFAP, aconitase, ENO1, ENO2, } \\
\text { CKB, TER ATPase, HSC71, } \\
\text { ALDH7A1, CCT2, DDAH1, } \\
\text { PDXK, PKM2, ATP synthase } \\
\text { subunit } \alpha, \text { GAPDH, UQCRC2, CS, } \\
\text { CK }\end{array}$ & $\begin{array}{l}\text { neuron structure, energy } \\
\text { metabolism, molecular } \\
\text { chaperone, } \\
\text { neurotransmission, }\end{array}$ & $\begin{array}{l}\text { Sorolla et al. 2008, Sorolla } \\
\text { et al. } 2010\end{array}$ \\
\hline & $\begin{array}{l}\text { r6/2 mouse } \\
\text { model }\end{array}$ & carbonylation & $\begin{array}{l}\text { Aco, ENO1, ENO2, CKBB, and } \\
\text { GAPDH }\end{array}$ & energy metabolism & Perluigi et al. 2005b \\
\hline \multirow[t]{3}{*}{ ALS } & $\begin{array}{l}\text { G93A-SOD1 } \\
\text { mouse model }\end{array}$ & carbonylation & $\begin{array}{l}\text { SOD1, TCTP, UCH-L1, } \alpha \beta- \\
\text { crystallin }\end{array}$ & $\begin{array}{l}\text { antioxidant, protein } \\
\text { degradation, molecular } \\
\text { chaperone, cell structure. }\end{array}$ & Poon et al. $2005 \mathrm{c}$ \\
\hline & & HNE-bound & DRP-2, HSP70, ENO1 & $\begin{array}{l}\text { neuron outgrow, molecular } \\
\text { chaperone, energy } \\
\text { metabolism }\end{array}$ & Perluigi et al. 2005a \\
\hline & $\begin{array}{l}\text { FALS mouse } \\
\text { model }\end{array}$ & nitration & $\begin{array}{l}\text { ENO1, ENO2, ATP synthase } \beta \\
\text { chain, HSC } 71\end{array}$ & $\begin{array}{l}\text { energy metabolism, } \\
\text { molecular chaperone }\end{array}$ & Casoni et al. 2005 \\
\hline
\end{tabular}


TABLE 2. (Continued)

\begin{tabular}{|c|c|c|c|c|c|}
\hline Pathology & Sample & $\begin{array}{l}\text { Oxidative } \\
\text { modification }\end{array}$ & Oxidatively modified proteins & $\begin{array}{l}\text { Altered biological } \\
\text { functions }\end{array}$ & References \\
\hline \multirow[t]{3}{*}{ DS } & $\begin{array}{l}\text { Amniotic fluid } \\
\text { from woman } \\
\text { carrying down } \\
\text { syndrome } \\
\text { fetus }\end{array}$ & carbonylation & $\begin{array}{l}\mathrm{CP}, \mathrm{TF}, \mathrm{Zn}-\alpha 2-\mathrm{CP}, \mathrm{RBP} 4 \text {, } \\
\text { APOA1, CoC } 9, \alpha-1 \beta-\mathrm{GP} \text {, collagen } \\
\alpha-1 \mathrm{~V} \text { chain, }\end{array}$ & $\begin{array}{l}\text { lipid metabolism, iron } \\
\text { homeostasis, inflammation }\end{array}$ & Perluigi et al. 2011 \\
\hline & \multirow[t]{2}{*}{$\begin{array}{l}\text { Ts1Cje mouse } \\
\text { model }\end{array}$} & $\begin{array}{l}\text { 3-hydroperoxy- } \\
9 \mathrm{Z}\end{array}$ & $\begin{array}{l}\text { ATP synthase F1 complex b } \\
\text { subunit, } \alpha \text {-enolase, TPI1 }\end{array}$ & energy metabolism, & Ishihara et al. 2009 \\
\hline & & HNE-bound & $\begin{array}{l}11 \text { E-octadecadienoic acid, NF } \\
\text { light polypeptide, internexin } \\
\text { neuronal intermediate filament, } \\
\text { enolase, Prx6, PGK, TPI }\end{array}$ & $\begin{array}{l}\text { neuron structure, energy } \\
\text { metabolism, antioxidant }\end{array}$ & Ishihara et al. 2009 \\
\hline
\end{tabular}

oxide (RNO). Distinct signaling events need different quantities of ROS/RNS, which include oxidative signaling (irreversible PTMs) and redox signaling (reversible PTMs). For example, radiation is often used as a therapy treatment of cancer, but exposure to radiation, especially under large dose radiation, may cause an increased risk of cardiovascular disease. 2D-DIGE and LC-MS/MS analysis of radiated mitochondrial proteins revealed proteome changes and functional impairment (Barjaktarovic et al., 2011). The presence of 3-NT in whole heart homogenate and heart mitochondria was measured by $2 \mathrm{D}$-Western blots with anti-3-NTantibodies. Biological aging contributed to the oxidative stress of 48 proteins (Barjaktarovic et al., 2011). Some enzymes responsible for energy production were oxidatively modified, which indicated cellular sources of ROS/RNS (Kanski et al., 2005). Oxidative modifications of protein thiols are important in redox regulation and can occur in cardiac tissue upon oxidative stress. Protein carbonylation is implicated in the pathogenesis of heart failure (HF) (Brioschi et al., 2012). M-type creatine kinase (M-CK) and alpha-cardiac actin are the major carbonylated proteins with higher levels in HF patients in comparison with controls.

\section{Cancer}

Disturbances of the redox balance in the cell may lead to chronic inflammation (Reuter et al., 2010), and a variety of biological responses are triggered, for example, cell adaptation, formation of DNA mutations and genetic instability (Scibior-Bentkowska \& Czeczot, 2009), which in turn could result in chronic diseases including cancer. Many oxidized PTMs have been identified in tumor cells with comprehensive redox proteomics approaches. $2 \mathrm{D}$-gel redox proteomics has been used to study protein expression and specific protein carbonylation of UVB-induced oxidative stress for the development of skin cancer. In these studies seven proteins were significantly more oxidized in irradiated cells compared to control cells (Perluigi et al., 2010a). In another study of UVB-induced skin cancer, lysine- and cysteine-labeled 2D-DIGE were used to measure protein expression changes and thiol activity (Wu et al., 2012). MALDI-TOF MS identified 89 proteins with significant changes and 37 proteins with differences in thiol activity. Proteins involved in redox regulation were up-regulated indicating the importance of redox-regulated proteins upon oxidative stress. In a similar study, tumor cells were subject to photodynamic treatment (PDT), which leads to oxidative modifications in cells. Samples were enriched by biotin-avidin affinity chromatography and separated and visualized by 2D-gel. MS identified 314 proteins, including carbonylation and reversible sulfenylation (Tsaytler et al., 2008).

Redox proteomics studies have been applied not only in skin cancer, but also other types of cancer-related pathology. For example, plasma peroxidation levels are significantly higher in cancer patients than controls (Haudek et al., 2008). Cancer cachexia can alter redox balance in fast- and slowtwitch limb and heart muscles of rats and a comprehensive examination of different types of oxidative PTMs study was performed. Carbonylation, 4-HNE, and MDA modification were determined by $2 \mathrm{D}$-gel redox proteomics method and found significant increase in comparison with controls (Marin-Corral et al., 2010). High levels of nitration and carbonylation have also been reported in the plasma of lung cancer patients (Pignatelli et al., 2001).

\section{Diabetes}

Impaired production of insulin can result in diabetes and this chronic disease plays important roles in the development of cardiovascular disease (Turchan et al., 2003). It is shown that oxidative stress is implicated in the development of diabetes (Yorek, 2003). High level blood glucose results in the formation of oxidized glucose, accelerating the formation of AGEs (Baynes, 1991). Additionally, lower intracellular GSH concentration is observed in diabetes patients in correlation with high ROS production (Dominguez et al., 1998). The concentration of glutathionyl hemoglobin beta chain is markedly increased in diabetic patients (Niwa et al., 2000). Additionally, nitric oxide overproduction occurs in type 1 diabetes patients (Hoeldtke et al., 2002). Carbonylation may contribute to activity loss of the sarco(endo)plasmic reticulum $\mathrm{Ca}^{2+}$-ATPase (SERCA2a), the ATP-driven pump that translocates $\mathrm{Ca}^{2+}$ from the cytoplasm to the lumen of the sarcoplasmic reticulum (Shao et al., 2011). After diabetic treatment of model rats, the ability of SERCA2a 
protein to hydrolyze ATP and transport $\mathrm{Ca}^{2+}$ was significantly reduced. Western blot and MS revealed the modification of carbonylation on SERCA2a residues.

\section{B. Neurodegenerative Diseases}

Neurodegenerative disorders such as AD, PD, or ALS are a heterogeneous group of diseases affecting the nervous system that present different etiologies. Some are hereditary, some are secondary to toxic or metabolic processes or both aspects are possible in each disorder. Neuropathologically, these neurodegenerative disorders are characterized by abnormalities of relatively specific regions of the brain and specific populations of neurons. During neurodegeneration, the brain undergoes both morphological and functional modifications affecting dendritic arborization, synapses, neurotransmission, circulation, and metabolism that are reflected in the alteration of motor and sensory systems, sleep, memory, and learning (Tabner et al., 2005). In each case, the molecular mechanisms involved in these changes have yet to be determined. Growing evidence, implicate the effects of OS, mitochondrial dysfunction and inflammatory insults as major contributing factors (Butterfield, 2006). Several authors investigating the role of OS suggested it as a causative or at least ancillary factor in the pathogenesis of major neurodegenerative diseases (Butterfield et al., 2012). Decreased levels of antioxidant enzyme activities have been reported in patients with PD or AD, and increased levels of lipid peroxidation, DNA and proteins oxidation have been seen in different brain regions of patients affected with PD and AD (Reed, 2011). Similar increases in markers of OS have also been seen in Huntington's disease, and in both familial ALS (fALS) and sporadic ALS (sALS) patients (Ferrante et al., 1997).

In the last two decades, much effort was made by researchers to better comprehend how oxidative damage could play a role in the pathogenesis of each disease. The advent of redox proteomics (Castegna et al., 2002a,b; Dalle-Donne, Scaloni, \& Butterfield, 2006) helped partially to fill this gap by gaining new insight into the relationships between OS and neurodegeneration. Redox proteomics studies lead to direct identification from brain, fluids or other biological samples, of a large number of oxidatively modified proteins potentially involved in the pathogenesis and/or progression of neurodegenerative diseases characterized by increased OS (Butterfield, 2006; Di Domenico et al., 2011; Butterfield et al., 2012). The use of redox proteomics helped to show the target of oxidative modification at the protein level suggesting specific (often common) patterns of oxidative damage during the progression of the above-mentioned neurodegenerative disorders (Butterfield \& Sultana, 2008). This new wealth of knowledge has provided great insights into mechanisms and potential targets for therapeutic strategies. Our laboratory pioneered studies aimed to provide new knowledge and better comprehension about the role of OS in the onset and progression of selected neurodegenerative disorders (Butterfield et al., 2012). All the redox proteomics results achieved by our and other laboratories using redox proteomics to investigate molecular mechanism altered by increased OS/NS during neurodegeneration are reported below (see Table 2). In addition redox proteomics provides essential information regarding protein modifications not only in neurodegenerative disorders but also in cancers or other pathologies.

\section{Alzheimer Disease and Its Early Forms}

Dementia is one of the most disabling disorders in the elderly and with the increase of life span the number is expected to raise becoming a greater medical and social problem. The main cause of senile dementia is $\mathrm{AD}$ (approximately 75\%). Clinically, $\mathrm{AD}$ is characterized by progressive loss of memory, language, reasoning, and other cognitive functions accompanied by concomitant behavioral, emotional, and social deterioration, all leading to dementia. The neuropathological hallmarks of the brain of $\mathrm{AD}$ patients are extracellular senile plaques containing amyloid- $\beta$ peptide $(A \beta)$ neurofibrillary tangles (NFTs) containing hyperphosphorylated tau, and loss of synapses in neurons of the cerebral cortex and hippocampus. Abundant evidence supports the notion that OS/NS stress has a major role in the pathogenesis of $\mathrm{AD}$. Oxidizing conditions during $\mathrm{AD}$ cause protein cross-linking and aggregation of $A \beta$ peptides and also contribute to aggregation of tau and other cytoskeletal proteins. $A \beta$ aggregates upon interaction with the nerve cell membrane induce a sequence of events that lead to the intracellular accumulation of ROS (Butterfield et al., 2012). A $\beta$ causes the oxidation of acyl chains of membrane lipids, disintegration of the neuronal membrane and, ultimately, cell death (Behl, 1997; Varadarajan et al., 2000). In addition to the direct induction of $\mathrm{OS}, \mathrm{A} \beta$ can also indirectly generate an oxidative microenvironment, for example, via the induction of mitochondrial dysfunction. $\mathrm{OS}$ in $\mathrm{AD}$ brain is indexed by increased total levels of protein carbonyls, protein nitration and protein-bound HNE for protein oxidation and lipid peroxidation respectively (Butterfield et al., 2006a; Butterfield \& Sultana, 2007), DNA and RNA oxidation are indexed by elevated levels of $8 \mathrm{OHdG}$ and $8 \mathrm{OHG}$ and sugar oxidative modification marked by increased glycation and glycoxidation.

\section{a. Redox proteomic in human brain tissue}

Redox proteomics techniques, applied to several brain regions from $\mathrm{AD}$ patients compared to healthy subjects, allowed the identification of many protein targets of oxidative modification during the neurodegenerative process. Studies designed to target protein carbonylation showed increased levels for creatine kinase (CK)-BB, glutamine synthase (GS), ubiquitin carboxyterminal hydrolase $(\mathrm{UCH}) \mathrm{L}-1$, dihydropyrimidinase-related protein 2 (DRP-2) [also called collapsin response mediated protein-2 (CRMP-2)], $\alpha$-enolase (ENO1) and heat shock cognate (HSC) 71 in AD inferior parietal lobule (IPL) compared to age-matched controls (Castegna et al., 2002a,b). Following studies performed on hippocampal region of $\mathrm{AD}$ subject compared to CTR demonstrated specific carbonylation of peptidyl prolyl cis-trans isomerase (Pin1), phosphoglycerate mutase (PGM) 1, UCHL-1, DRP-2, carbonic anhydrase (CA) II, triose phosphate isomerase (TPI), ENO1, and soluble NEMsensitive factor attachment protein $\gamma(\gamma$-SNAP) (Sultana et al., 2006a,b). The impairment of the functionality of the proteins found oxidized in these studies strictly correlate with some of the main features of $\mathrm{AD}$ pathology such as the impairment in cellular metabolic processes (PET studies demonstrated decreased glucose utilization in $\mathrm{AD}$ brain), the inhibition of cellular degradation machinery and synaptic failure. Korolainen et al. (2006) applied a similar redox proteomics approach to frontal cortex samples of AD patients compared to healthy subjects showing a decrease for carbonyls 
in malate dehydrogenase (MDH) 1 , glutamate dehydrogenase $(\mathrm{GDH}), 14-3-3$ protein $\varsigma / \delta$, aldolases $\mathrm{A}$ and $\mathrm{C}$, and increased oxidation of CA.

Redox proteomics studies on specific protein nitration identified a large number of proteins, in AD hippocampus and IPL compared to control brain, which are involved in various cellular functions such as energy metabolism, structural maintenance, $\mathrm{pH}$ regulation, and mitochondrial function. These nitrated proteins include, in AD IPL, $\gamma$ enolase (ENO2) and ENO1, lactate dehydrogenase (LDH), neuropolypeptide h3, TPI, and $\beta$-actin (Castegna et al., 2003), while in AD hippocampus, ENO1, glyceraldehyde-3-phosphate dehydrogenase (GAPDH), ATP synthase $\beta$-chain, CA-II, and voltage-dependent anion channel (VDAC) protein (Sultana et al., 2006c).

Proteomics studies identified regionally specific HNE modification of proteins, that is, ATP synthase, GS, Manganese superoxide dismutase (MnSOD), and DRP-2 in AD hippocampus and $\alpha$-enolase, aconitase, aldolase, peroxiredoxin (PRX) 6, and $\alpha$-tubulin in AD cortex (Perluigi et al., 2009). Some of these proteins were previously found to be either nitrated or carbonylated in AD. The appearance of different oxidative indices in target proteins modified by both protein carbonyls, 3-NT and HNE-bound suggest that these specific proteins are highly vulnerable to oxidative modification and may be involved in $\mathrm{AD}$, supporting the role of OS in AD.

Redox proteomics studies targeting glutathionylated proteins have been performed on IPL of AD subjects compared to control subjects. This study revealed the increased glutathionylation of a number of proteins, that is, deoxyhemoglobin, $\alpha$ crystallin B, glyceralde-3-phosphate dehydrogenase (GAPDH), and ENO1. GAPDH and ENO1 were also shown to have reduced activity in the AD IPL. This study demonstrates that specific proteins are sensitive to S-glutathionylation, which most likely is due to their sensitivity to cysteine oxidation initiated by the increase in OS in the AD brain (Newman et al., 2007).

Amnestic mild cognitive impairment (MCI) is generally referred to the transitional zone between normal cognitive function and early dementia or clinically probable AD. OS that plays a significant role in $\mathrm{AD}$ is increased in the superior/ middle temporal gyri of MCI subjects. Redox proteomics studies in MCI hippocampus led to the identification of ENO1, GS, pyruvate kinase (PK) M2, and Pin1 as specifically carbonylated proteins (Butterfield et al., 2006a). Interestingly, several proteins such as ENO1, Pin1, and GS are common targets of carbonylation in both $\mathrm{AD}$ and MCI. The functions of these proteins are important not only in regulating energy metabolism, but were also linked to alterations in protein conformation, tau hyperphosphorylation, APP processing, and glutamate regulation, that are all thought to contribute to the progression of neurodegenerative processes in AD. However, the presence of other different proteins oxidatively modified suggests that the specific targets of OS might be stagedependent. In regard to protein nitration in MCI samples compared to controls, increased in protein-resident 3-NT levels for $\mathrm{MDH}, \mathrm{ENO} 1$, glucose regulated protein precursor, aldolase, glutathione- $S$-transferase (GST) $\mathrm{Mu}$, multidrug resistant protein (MRP)-3, and 14-3-3 protein $\gamma$ were identified in MCI IPL, while, ENO1, MDH, PRX 6, DRP-2, fascin 1, and heat shock protein (HSP) A8 were identified by redox proteomics in MCI hippocampus (Sultana et al., 2007). Simi- larly to carbonylation some of the targets of protein nitration are in common between MCI and AD, suggesting that these brain proteins that contribute to dysfunction of molecular processes, such as energy metabolism or synaptic connections seen in $\mathrm{AD}$, may be involved in progression of $\mathrm{AD}$. In MCI hippocampus and cortex, increased levels of protein-bound HNE observed for LDH B, phosphoglycerate kinase (PGK), heat shock protein 70 (HSP 70), ATP synthase, PK, $\beta$-actin, elongation factor $\mathrm{Tu}(\mathrm{EF}-\mathrm{Tu})$, and translation initiation factor $\alpha$ as identified by redox proteomics (Reed et al., 2008). Again the overlap of proteins involved in energy metabolism, neuritic abnormalities, cell cycle, tau phosphorylation, $\mathrm{A} \beta$ production, transcription and translation, mitochondrial abnormalities, and antioxidant system between MCI and AD is consistent with the notion that these pathways could be involved in the progression of MCI to AD.

Early AD (EAD) is considered a transitional stage between MCI and AD. In redox proteomics studies comparing MCI, EAD, and control (CTR) IPL samples targeting carbonylated proteins MCI samples had four proteins significantly more oxidized than CTR while EAD had three proteins more oxidized than CTR. These proteins are: HSP 70, CAII, syntaxin binding protein I (SBP1), and mitogen-activated protein kinase (MAPK) I for MCI and PGM1, fructose bisphosphate aldolase (FBA)-C, and GFAP for EAD (Sultana et al., 2010).

As with carbonylation protein nitration also is increased in brain from subjects with EAD compared with age-matched controls. In the EAD brain, redox proteomics analysis identified the increased nitration of PRX2, TPI, GDH, neuropolypeptide h3, PGM1, H-transporting ATPase, ENO-1, and FBA-A (Reed et al., 2009a).

Redox proteomics analysis of protein-bound HNE identified six proteins found to be excessively oxidatively modified by this lipid peroxidation product in EAD IPL compared to agerelated control brain. These proteins were MnSOD, DRP2, ENO1, MDH, TPI, and F1 ATPase, $\alpha$ subunit that, respectively, play roles in antioxidant defense, neuronal communication and neurite outgrowth, and energy metabolism (Reed et al., 2009b). ENO1, TPI, PGM1, and ATP synthase are found as common targets of oxidation in late-stage $\mathrm{AD}$ and EAD brain. The proteins enolase, neuropolypeptide h3, ATP synthase, and FBA appear to be oxidized in brain from subjects at each stage of AD: late-stage $\mathrm{AD}, \mathrm{EAD}$, and MCI suggesting that their oxidation is an early event and contribute to progression of $\mathrm{AD}$.

Preclinical AD (PCAD) refers to the early phase of $\mathrm{AD}$, before clinical signs and symptoms appear. Redox proteomics studies comparing the IPL region of PCAD subjects with MCI subjects identified increased carbonylation levels in MCI for HSP90 and ENO1 (Aluise et al., 2011). Since MCI patients have memory loss, while PCAD patients have normal cognition, the impairment of these proteins conceivably could contribute to memory loss in MCI.

Summarizing the redox proteomics analyses of brain proteins at different stages of $\mathrm{AD}$ is evident that protein oxidation highly correlates with the clinical features, pathology, and biochemistry of $\mathrm{AD}$, demonstrating the strength and utility of the redox proteomics approach. Oxidative dysfunction of proteins involved in energy metabolism, antioxidant response, protein degradation, excitotoxicity, neuronal structure, and mitochondrial abnormalities are likely involved in neurodegeneration at various stages of this dementing disorder. The 
identification of these common targets of protein oxidative modification among different phases of disease is consistent with the concept that losses of function of these proteins have an important role both in the molecular basis of this disorder and in its progression from stage to stage of $\mathrm{AD}$.

\section{b. Redox proteomics in biological fluids}

Surprisingly, only a few reports are present about specific protein oxidation in plasma/serum and cerebrospinal fluid (CSF) of AD patients and its early form compared to healthy subjects. CSF is the most proximal fluid in the CNS and logical source to find any significant alteration directly related to the pathology. Therefore, the composition of CSF partially reflects cerebral metabolic changes and enables screening of ongoing pathophysiological process in brain. By using redox proteomics, an increased degree of carbonylation was shown in one study for one protein only, $\lambda$-chain precursor protein in CSF of $\mathrm{AD}$ patients compared with controls (Korolainen et al., 2007). In another study, Yu et al. investigated oxidized levels of glycoproteins in plasma from AD patients. These researchers reported increased levels of carbonylation for glycosylated hemopexin and transferrin in the $\mathrm{AD}$ subjects compared to controls, suggesting systemic derangements in heme and iron redox homeostasis and activation of the acute phase response in $\mathrm{AD}$ (Yu et al., 2003).

The first redox study on plasma exerted by Choi et al. (2002) identified increased levels of carbonyl groups in AD compared with controls for fibrinogen gamma chain precursor and $\alpha 1$ antitrypsin precursor. A recent study on carbonylated proteins in $\mathrm{AD}$ and $\mathrm{MCI}$ compared with age-matched controls identified four additional proteins (Cocciolo et al., 2012). Three proteins were more oxidized in $\mathrm{AD}$ with respect to CTR: haptoglobin (Hp) $\beta$ chain, serotransferrin, and $\alpha 2$ macroglobulin, while only one protein, Hp $\beta$ chain, was more oxidized in MCI versus CTR (Cocciolo et al., 2012). Interestingly, Hp $\beta$ chain was found to be more oxidized both in MCI versus CTR (3.34-fold) and in AD versus MCI with the oxidation level that gradually increased from MCI to AD. This result suggests an impairment of $\mathrm{Hp} \beta$ chain that reflects the pathology progression and supports the involvement of impaired extracellular chaperones in the formation of $A \beta$ aggregates at plasma level during AD.

c. Redox proteomics in selected animal and cellular models of $A D$ The J20 Tg mice strain has mutations in human APP corresponding to the Swedish (670/671 KM - NL) and Indiana $(717 \mathrm{~V} \rightarrow \mathrm{F})$ familial forms of $\mathrm{AD}$ that results in several aspects of $\mathrm{AD}$ pathology, such as $\mathrm{A} \beta$ accumulation, neuritic plaque formation, and memory deficits. Oxidative stress in J20 Tg mice can be directly correlated with these pathological hallmarks (Butterfield et al., 2010). Redox proteomics analysis targeting protein-resident $3-\mathrm{NT}$ in this AD model compared with wild type (C57BL/J6) demonstrated increased nitration for phosphatidylethanolamine-binding protein (PEBP) 1 and Pin-1 (Robinson et al., 2011). Pin-1 was observed oxidatively modified in the hippocampus of AD and MCI brain (Sultana et al., 2006a) and has been heavily implicated in $\mathrm{AD}$, through its regulation of phosphorylation/dephosphorylation of tau and production of $A \beta$ (Butterfield et al., 2006b).

Redox proteomics of synaptosomes treated in vitro with $A \beta$ (1-42) showed oxidation of $\beta$ - and $\gamma$-actin, glial fibrillary acidic protein (GFAP), H+-transporting two-sector ATPase (ATP synthase), SNBP1, GDH, GS, excitatory amino-acid transporters (EAAT) 2, DRP-2, and EF-Tu (Boyd-Kimball et al., 2005). The study on synaptosomes demonstrates that acute exposure to $A \beta(1-42)$ leads to the oxidation and impairment of most of the pathways already observed as dysfunctional in $\mathrm{AD}$ brain and supports the role of $\mathrm{A} \beta(1-42)$ in the pathogenesis of AD.

Redox proteomics analysis of rat brain injected in vivo with A $\beta \quad(1-42)$ into the nucleus basalis magnocellularis (NBM) compared with saline-injected control at 7 days postinjection examined the regional in vivo induced protein oxidation and identified a number of oxidatively modified proteins (Boyd-Kimball et al., 2005). In the cortex, GS and tubulin $\beta$ chain $15 / \alpha$ were identified, while in the NBM, 143-3 $\zeta$ and HSP 60 were identified as significantly oxidized. Extensive oxidation was detected in the hippocampus in which 14-3-3 $\zeta$, $\beta$-synuclein, pyruvate dehydrogenase (PDH), GAPDH, and PGM1 were identified as oxidatively modified. The results suggest that $A \beta(1-42)$-induced $O S$ in rat brain mirrors some of those proteins oxidized in $\mathrm{AD}$ brain, and provide new and further insights into the mechanism of neurodegeneration driven by $\mathrm{A} \beta$ deposition.

In the following study proteomics techniques were employed to identify proteins that are specifically oxidized in a transgenic $C$. elegans expressing human $A \beta(1-42)$ in body wall muscle (CL4176) (Boyd-Kimball et al., 2006). Sixteen proteins were found to be oxidatively modified in C. elegans expressing $\mathrm{A} \beta$ (1-42) compared to CTR and were involved in a variety of cellular functions including energy metabolism, proteasome function, cellular structure, lipid transport, and signal transduction. Moreover, to evaluate the role of protein aggregation per se in OS and to control for non-specific protein oxidation resulting from muscle dysfunction itself, a transgenic C. elegans strain expressing a green fluorescent protein (GFP) fusion protein and a transgenic $C$. elegans strain expressing the ypkA subunit of Yersinia pseudotuberculosis, a serine/threonine kinase known to affect the cytoskeleton (XA1440) were examined. Five proteins were identified to be oxidatively modified in $C$. elegans expressing aggregated GFP, and one protein oxidatively modified in C. elegans expressing ypkA (Boyd-Kimball et al., 2006). The only common proteins between the three groups were proteasomal subunits, suggesting that oxidative damage to the proteasome may be a general result of cellular toxicity leading to muscle dysfunction. Instead the results about A $\beta$ (1-42) driven protein oxidation provide further important evidence on the toxic effect of $A \beta(1-42)$ and insights into the neurodegenerative effects of $A \beta(1-42)$ in the pathogenesis of $A D$.

\section{Aging}

Aging is a complex biological process characterized by a gradual decline in biochemical and physiological functions of most organs and is considered one of the most significant risk factors for age-related neurodegenerative diseases, such as AD. The aging process is accompanied by a general deterioration in the CNS functionality, which is particularly vulnerable to oxidative injury. The oxidative damage to cellular macromolecules accumulates with age and has been postulated to be the main, but not the only, type of endogenous damage strongly involved in the aging process. 
Several studies have indicated that the levels of oxidized proteins, exhibiting carbonyl groups, increase progressively with age (Carney et al., 1991; Cini \& Moretti, 1995; DogruAbbasoglu et al., 1997; Butterfield \& Sultana, 2008). In addition the loss of protein sulfhydryl groups and the reduced activity of important metabolic enzymes have been documented to occur in brain as a function of aging (Keller et al., 2000b; Butterfield \& Kanski, 2001; Zhu, Carvey, \& Ling, 2006).

Senescence-accelerated-prone mice (SAMP), exhibit accelerated aging with a shortened life span and often increased amyloidosis, in contrast to senescence-acceleratedresistant mice (SAMR), which exhibit normal aging characteristics (Miyamoto, 1997). SAMP8 mice exhibit age-dependent learning and memory deficits (Yagi et al., 1988). Therefore, the SAMP8 is a model for studying age-related cognitive impairments and amyloidosis that might lead to insight into $\mathrm{AD}$ onset and progression (Poon et al., 2004). Analysis of protein carbonylation by redox proteomics revealed increased levels for LDH-2, DRP2, $\alpha$-spectrin, and $\mathrm{CK}$ in the brain of 12-month-old SAMP8 mice when compared with the 4-month-old SAMP8 brain. These results suggest the oxidized proteins may contribute to the abnormal metabolism and neurochemical changes seen in SAMP8 mice and might ultimately contribute to their deficits in learning and memory. Interestingly decreasing the production of $\mathrm{A} \beta$ by giving an intracerebroventricular injection of a 42 mer phosphorothiolated antisense oligonucleotide (AO) directed at the A $\beta$ region of the APP gene reduced lipid peroxidation, protein oxidation, and improved cognitive deficits in aged SAMP8 mice (Poon et al., 2004). Furthermore, the oxidative modification of aldolase, coronin $1 \alpha$, and PRX2 are significantly reduced after reduction of $A \beta$ in vivo as a consequence of administration of $\mathrm{AO}$ against the $\mathrm{A} \beta$ region of APP (Poon et al., 2005a).

Redox proteomics studies conduced on aged rats (28 months old) compared with adult (12 months old) in four different brain region, that is, hippocampus, cortex, striatum, and cerebellum demonstrated the increased carbonylation of a number of proteins that are: HSP90, Cytochrome b-c1, CKB, MDH, $\alpha$-enolase, DRP2, GS, GDH, PK M1/M2 FBA-C, ATP synthase in hippocampus region; $\operatorname{Prdx} 2$, Guanine nucleotidebinding protein (GNBP) $\beta-1$, CK B, V-ATP-B, HSP70, Ser/thrprotein phosphatase-2B, aldehyde dehydrogenase $\mathrm{ADH}, \alpha$ centractin, TPI, GAPDH, aspartate aminotransferase (AAT), PK M1/M2, ATP synthase, FBA-A in cortex region; $\alpha$-tubulin-1A GRP (glucose regulated protein) 78, HSP70, adenylate kinase (AK), EF-Tu, PK M1/M2, aconitate hydratase (ACH), TPI, GAPDH in striatum region; HSC 71, $\alpha$-tubulin, $\mathrm{MDH}$, isocitrate dehydrogease (IDH), V-ATPase, PK M1/M2, synapsin-2, AAT, PGK1 VDAC, AK in cerebellum region (Perluigi et al., 2010b). The oxidatively modified proteins found oxidatively modified in this study are in very similar to those found in $\mathrm{AD}$ brain (previously discussed), thus confirming that aging is a major risk factor for developing neurodegenerative diseases. Although the etiologies are different and likely multifactorial, aging and agerelated neurodegenerative diseases share some common pathological mechanisms, among which energy failure at mitochondrial level is one of the most crucial for neuronal dysfunction.

In other redox and expression proteomics studies of aging, L-acetylcarnitine, a proposed therapeutic agent for aged related neurodegenerative disorders associated with oxidative stress, revealed key molecular pathways, including glutamate signaling, as protected in brain of aged rats treated from 16 to 28 months of age with this compound (Poon et al., 2006a). Brain proteins associated with mitochondrial function, glutamate signaling, and protein synthesis were protected in rats kept on a caloric restricted diet, a known means of increasing lifespan (Poon et al., 2006b). A comparison of olfactory proteins of differential expression and/or oxidative modification with altered gene levels in aged mice showed remarkable correspondence (Poon et al., 2005d).

\section{Parkinson Disease}

Parkinson disease (PD) is the second most prevalent degenerative disease of the nervous system affecting roughly $1 \%$ of individuals over the age of 65 . The majority of PD cases are likely sporadic but there are a number of rare, genetic causes of this disease. Mutations in $\alpha$-synuclein, parkin, Parkinson disease protein 7 (DJ-1), leucine rich repeat kinase 2 (LRRK2), $\mathrm{UCH}-\mathrm{L} 1$, and PTEN-induced putative kinase protein 1 (PINK1) contribute to early onset familial PD. PD-affected patients suffer from progressive loss of dopaminergic neurons prevalently in the substantia nigra pars compacta, as well as accumulation of Lewy bodies, and more widespread neuronal changes that cause complex and variable motor and non-motor symptoms. OS plays a dramatic role in PD, being involved in dopamine cell degeneration, mitochondrial dysfunction, excitotoxicity, nitric oxide toxicity, $S$-nitrosylation and inflammation. Oxidative damage to lipids, proteins, and DNA occurs in PD; increased levels of HNE (that as showed above reacts with protein), acrolein, MDA, isoprostanes, and neuroprostanes have been reported. Oxidative damage is well known in PD brains (Yoritaka et al., 1996; Alam et al., 1997; Floor \& Wetzel, 1998) and has been associated with the overexpression of wild-type or mutant $\alpha$-synuclein (Ostrerova-Golts et al., 2000). Increased oxidative damage in several metabolic enzymes including GAPDH, FBA-A, ENO1, and SOD have been observed in sporadic cases of PD, contributing to the hypothesis of reduced glucose metabolism in neurodegeneration (Ferrer et al., 2011). Although OS has been well documented in Parkinson disease, few redox proteomics experiments involving human subjects have been reported. Mutations in $\alpha$-synuclein cause familial $\mathrm{PD}$, and overexpressing mutant human $\alpha$-synuclein (A30P or A53T) causes degenerative changes in mouse and Drosophila models of PD (Junn \& Mouradian, 2002). Using redox proteomics, several significantly oxidatively modified brain stem proteins were identified in symptomatic mice with overexpression of A30P mutation in $\alpha$-synuclein compared with the brain proteins from the non-transgenic mice (Poon et al., 2005b). These proteins were identified as CA-II, ENO1, LDH2. The activities of these enzymes were also significantly decreased in the A30P $\alpha$-synuclein transgenic mice brains when compared with the brain proteins from non-transgenic control. This observation is consistent with the notion that oxidative modification of proteins leads to loss of their activities (Butterfield \& Stadtman, 1997). These findings suggest that proteins associated with impaired energy metabolism and mitochondria are particularly prone to OS associated with A30P-mutant $\alpha$-synuclein. Moreover because each of the redox proteomics studies identified oxidatively modified brain proteins associated with mitochondria, there is strong evidence to 
suggest that mitochondrial dysfunction and aggregated synuclein is a key player in PD pathogenesis.

An interesting approach was followed by Hastings and coworkers, which evaluate protein alterations in rat brain mitochondria immediately following in vitro exposure to dopamine quinone (Van Laar et al., 2008). Oxidation of dopamine to reactive metabolites, ROS, and dopamine quinone is thought to contribute to the oxidative stress, mitochondrial dysfunction, and dopaminergic neuron degeneration in PD. Among the proteins with altered expression a major significance is demonstrated by MtCK, mitofilin, mortalin and $75 \mathrm{kDa}$ subunit of Complex I that suggest that mitochondrial protein alterations resulting from DA oxidation may lead to impaired mitochondrial protein import, cristae reorganization, and PTP formation. These in turn deteriorate key proteins involved in the Krebs cycle and electron transport chain (ETC) function, leading to increased ROS formation and creating a vicious cycle of oxidative damage (Van Laar et al., 2008).

The LRRK2 gene has been identified as the most common causative gene of autosomal-dominant inherited and idiopathic PD (Dachsel \& Farrer, 2010). In a C. elegans model coexpressing human LRRK2 (WT, G2019S, and R1441C strains) with tau our group performed redox proteomics analysis showing that the co-expression of human mutated LRRK2 leads to increased protein oxidation (Di Domenico et al., 2012). The redox proteomics results regarding protein-bound $\mathrm{HNE}$ of these transgenic models showed increased protein oxidative modification for 17 proteins in G2019S::Tau compared to Tau, and 10 proteins in the comparison with non-transgenic worms. The number of proteins oxidatively modified identified by redox proteomics is consistent with the results of the total HNE levels, demonstrating increased lipid peroxidation in the presence of G2019S::Tau. C. elegans transgenic models with R1441C::Tau co-expression present similar results to those with G2019S::Tau co-expression, suggesting common mechanisms that lead to increased OS. The R1441C::Tau co-expression identified HNE modification of 4 and 9 proteins in the comparison with Tau and non-transgenic strains, respectively (Di Domenico et al., 2012). The redox proteomics data are consistent with the notion that the trend of oxidation is a result of the interaction of mutated LRRK2 and Tau and show the oxidation of proteins that are involved mainly in energy metabolism, protein degradation, especially autophagy, and protein biosynthesis. These results suggest that LRRK2 might interact with Tau through the activation of several downstream signals and the mutation could enhance LRRK2 effects on tau PTM and compartmentalization. Interestingly, previous functional studies of PD-related genes implicate dysfunction of mitochondria, autophagy, and the stress response in the pathophysiology of PD (Plowey et al., 2008; Saha et al., 2009; Dachsel \& Farrer, 2010) strengthening the relationship of mutated LRRK2, tau phosphorylation and their interplay in the progression of PD.

\section{Huntington Disease}

Huntington disease (HD) is a neurodegenerative disease resulting from the genetically programmed degeneration of neurons in the striatum. This pathology causes uncontrolled movements of harm, legs, torso and head, loss of intellectual faculties, and emotional disturbances that develop over a period of 15-20 years (Kremer, Weber, \& Hayden, 1992). Death generally results from complications of immobility. HD is a progressive autosomal dominant disorder caused by expansion of CAG trinucleotide repeats in exon 1 of the huntingtin gene on chromosome 4 that encodes a stretch of polyglutamines in the $N$-terminus of the huntingtin protein (Htt) (Snell et al., 1993; Beal \& Ferrante, 2004). Neuropathologically, the disease is characterized by bilateral striatal atrophy with marked neuronal loss and astrogliosis within the caudate and putamen. The etiology of this disease includes the generation of excitotoxic events, the alteration in energy metabolism and mitochondrial dysfunction, the resulting OS, and $\mathrm{Htt}$ aggregation (Perez-De La Cruz \& Santamaria, 2007). These factors are strictly interconnected, making it difficult to know whether OS represents a primary cause of neuronal death, or a physiological process along the way of neuronal death. An oxidative imbalance exists in HD, as levels of lipid peroxidation are increased and antioxidant enzyme activity is reduced, and consistent with this suggestion, antioxidant supplementation appeared to slow the progression of animal models of the disease (Andreassen et al., 2001).

Redox proteomics experiments have been performed in human HD brain and in the $\mathrm{r} 6 / 2$ transgenic mouse model of the disease. The r6/2 transgenic mouse expresses exon 1 of the human HTT gene, which contains $150 \mathrm{CAG}$ repeats. These mice develop symptoms typical of those presented in HD, including poor motor coordination and cognitive decline (Li, Popovic, \& Brundin, 2005). Involuntary muscle control is a staple of this disease's pathology, supported by redox proteomics identification of the oxidative modification of several energy-related proteins: aconitase, ENO1 and ENO2, CKBB, and GAPDH (Perluigi et al., 2005b). This animal model study correlates with HD features like bioenergetic defects and mitochondrial dysfunction that play a key role in HD progression (Josefsen et al., 2010; Turner \& Schapira, 2010). Redox proteomics studies on HD brain samples compared to CTR showed increased protein carbonyls levels and GFAP, aconitase, ENO1, and $\mathrm{CKB}$ were identified as the main targets of oxidation (Sorolla et al., 2008). Recently, the same group identified 13 other differentially carbonylated proteins in HD compared to CTR, including enzymes involved in the glycolytic pathway and mitochondrial proteins related to ATP production (Sorolla et al., 2010). In particular, carbonylation of pyridoxal kinase and antiquitin 1 , both involved in the metabolism of pyridoxal 5phosphate, the active form of vitamin B6, was linked by the authors to the alterations in the synthesis of glutathione, GABA and dopamine, the latter two neurotransmitters known to play a key role in HD pathology. Taken together, these results indicate that OS and damage to specific macromolecules would participate in the disease progression in human as well as animal models of HD.

\section{Amyotrophic Lateral Sclerosis}

Amyotrophic lateral sclerosis (ALS) is a rapidly progressive neurodegenerative disease in which all voluntary muscle control is lost within 5 years of diagnosis. ALS affects motor neurons of the cerebral cortex, brainstem, and the anterior horn of the spinal cord (Cleveland \& Rothstein, 2001). The majority of ALS clinical presentations are sALS, with fewer than $10 \%$ of ALS cases inherited in an autosomal dominant manner, that is, fALS. Both sALS and fALS are clinically indistinguishable and show 
similar features. The real problem is the lack of in-depth knowledge of the molecular causes of ALS, as mutations in the $\mathrm{Cu}, \mathrm{Zn}-\mathrm{SOD}$ (SOD1) gene account for only $20 \%$ of familial ALS. More than 100 SOD1 mutations have been identified in fALS patients (Andersen, 2000), most of which result from substitution of one single amino acid, such as SOD1 ${ }^{\mathrm{G} 85 \mathrm{R}}$, $\mathrm{SOD} 1^{\mathrm{G} 37 \mathrm{R}}$, and SOD1 ${ }^{\mathrm{G} 93 \mathrm{~A}}$. It is now well established that SOD1-mediated toxicity in ALS is due to a "gain" of toxic properties that are independent of SOD1 activity (Gurney, 1997). Nonetheless, recent evidence suggests that OS plays a central role in ALS as well. Elevated PCO levels have been reported in the spinal cord, motor cortex and in central nervous tissue from sALS cases, and increased 3-NT levels were found within spinal cord motor neurons in both SOD1-fALS and fALS patients (Abe et al., 1995; Shaw et al., 1995; Ferrante et al., 1997). Lipid peroxidation was detected in spinal cord from sALS patients (Shibata et al., 2001), and levels of 8-OHdG were elevated in whole cervical spinal cord from ALS subjects (Fitzmaurice et al., 1996). The G93A-SOD1 transgenic mouse model, in which an Ala for Gly substitution occurs at position 93, has been thoroughly investigated in ALS research. This mouse overexpresses mutant human SOD1 and exhibits the agedependent motor neuronal characteristics associated with ALS (Dalle-Donne, 2007). Studies from our laboratory and others applied redox proteomics approaches to identify selective protein modifications in the spinal cord of G93A-SOD1 transgenic mice in comparison with wild-type mice (Perluigi et al., 2005a). Perluigi et al. (2005a) identified proteins that were significantly modified by $\mathrm{HNE}$ in the spinal cord tissue of a model of fALS, G93A-SOD1 transgenic mice, including DRP2 , HSP70, and, $\alpha$-enolase. By redox proteomics, our laboratory also identified the proteins that showed increased carbonyl levels in the spinal cord of G93A-SOD1 transgenic mice compared with those of wild-type mice: SOD1, translationally controlled tumor protein (TCTP), UCH-L1, and $\alpha \beta$-crystallin (Poon et al., 2005c). Taken together, these observations emphasize the role of OS in ALS and identified UPR and protein degradation pathway as main targets of oxidation, implying that their dysfunction might be involved in ALS progression. Casoni et al. (Casoni et al., 2005) showed increased nitration of ENO1 and ENO2, ATP synthase $\beta$ chain, and HSC 71 protein and actin in presymptomatic fALS mice using a redox proteomics approach. These works confirm the oxidation of proteins that are part of UPR and suggest the impairment of protein form energy metabolism pathway. So far, proteomics application to ALS research has been only limited to animal models, however, these studies provided many interesting new insights on disease onset and progression.

\section{Down Syndrome}

Down syndrome (DS) is the most common genetic cause of mental retardation that arises from the triplication of the entire, or even part of chromosome 21 (trisomy 21). After reaching 4045 years of age DS patients develop a form of dementia that has almost identical clinical and neuropathological characteristics of $\mathrm{AD}$. Although the genetic alterations are responsible of the major clinical presentations of the disease such as craniofacial abnormalities, small brain size, accelerated aging, and cognitive defects, additional environmental factors seem to play an important role in determining the severity of multiple pheno- types. AD like dementia in DS population is characterized by the presence of senile plaques and NFTs and by cholinergic and serotonergic reduction (Perluigi \& Butterfield, 2012). However, although most DS patients have plaques early in life and even in the fetus, it is only very later on that they may develop AD. The overexpression of the APP gene expressed on chromosome 21 is likely related to the overproduction of $A \beta(1-42)$ peptide, the major protein in the SPs, which is considered one of the important factors leading to the development of the $\mathrm{AD}$ pathology in DS subjects.

The role of OS in DS clinical phenotype is supported by a considerable number of studies (Iannello et al., 1999; Cenini et al., 2012). Increased oxidative damage is demonstrated by increased lipid peroxidation and oxidative DNA damage (Jovanovic, Clements, \& MacLeod, 1998), which indicate that the disease correlate with a "pro-oxidant state." However, the overwhelmed antioxidant defenses, both enzymatic and nonenzymatic, associated with DS highly complicate the understanding of the factor contributing to the outcome of DS phenotype. OS is known to occur in DS from very early stages: already during embryonic development mitochondrial dysfunction has been reported as a marker of oxidative damage (Arbuzova, Hutchin, \& Cuckle, 2002). Previous studies investigating the role of OS in DS showed increased levels of TBARS in the brains of DS patients, total protein carbonyls and AGEs in the cortex from DS fetal brain compared with controls (Odetti et al., 1998) and a marked accumulation of $80 \mathrm{HG}$, oxidized protein, 3-NT, in the cytoplasm of cerebral neurons in DS (Nunomura et al., 2000). In a redox proteomics study on amniotic fluid from mothers carrying a DS fetus specific oxidation of a number of proteins has been observed (Perluigi et al., 2011). The identified proteins are: ceruloplasmin and transferrin, zinc- $\alpha 2$-glycoprotein, retinol-binding protein (RBP) 4 , apolipoprotein (Apo) A1, complement C9, $\alpha$-1 $\beta$-glycoprotein, collagen $\alpha-1 \mathrm{~V}$ chain (Perluigi et al., 2011). Interestingly these proteins are all part of pathways highly challenged and with critical relevance in the clinical outcome of DS such as lipid metabolism, iron homeostasis, and inflammation. The result of this study indicates that oxidative damage is an early event in the DS pathogenesis and might contribute to the development of deleterious DS phenotypes, including abnormal development and AD-like neuropathology. Ishihara et al. identified, in a redox proteomics study, ATP synthase mitochondrial F1 complex b subunit, ENO1, and TPI1 as proteins modified by 3-hydroperoxy-9Z, 11 E-octadecadienoic acid and neurofilament light polypeptide, internexin neuronal intermediate filament, ENO2, PRX6, PGK1, and TPI as modified by HNE-bound (Ishihara et al., 2009). Dysfunction of these proteins results in the impairment of energy metabolism, neuronal structure, and antioxidant response shading some light in the possible mechanism dysfunctional in DS.

\section{CONCLUSIONS}

The growth of redox proteomics techniques has lead to detection and quantification of oxidative PTMs such as PCO, 3-NT, AGEs, protein glutathionylation, and AOPPs. Continued advances in redox proteomics gel-based and non-gel based MS approaches will further the applicability of this field for understanding disease. As discussed herein, insight to numerous important diseases such as kidney and cardiac disease, diabetes, 
cancer, and neurodegenerative disorders such as AD, PD, ALS, and DS has been gained with redox proteomics. However, future work in this area will allow better understanding of the role of oxidative stress and redox signaling in biological processes.

\section{ABBREVIATIONS}

\begin{tabular}{|c|c|}
\hline 2-DE & two-dimensional electrophoresis \\
\hline $3-\mathrm{NT}$ & 3-nitrotyrosine \\
\hline AAS & 2-amino-adipic semialdehyde \\
\hline AAT & aspartate aminotransferase \\
\hline $\mathrm{ACH}$ & aconitate hydratase \\
\hline $\mathrm{AD}$ & Alzheimer disease \\
\hline $\mathrm{ADH}$ & aldehyde dehydrogenase \\
\hline AK & adenylate kinase \\
\hline AOPPs & advanced oxidation protein products \\
\hline APCI & atmospheric pressure chemical ionization \\
\hline Apo & apolipoprotein \\
\hline ARP & aldehyde reactive probe \\
\hline ATP synthase & $\mathrm{H}+$-transporting two-sector ATPase \\
\hline $\mathrm{CA}$ & carbonic anhydrase \\
\hline CKBB & creatine kinase $\mathrm{BB}$ \\
\hline CKD & chronic kidney disease \\
\hline cPILOT & combined precursor and isotopic labeling \\
\hline $\mathrm{CuAAC}$ & $\begin{array}{l}\mathrm{Cu} 1+\text {-catalyzed azide-alkyne }[3+2] \text { cycload- } \\
\text { dition }\end{array}$ \\
\hline DNPH & 2,4-dinitrophenylhydrazine \\
\hline DRP-2 & dihydropyrimidinase-related protein 2 \\
\hline DS & Down syndrome \\
\hline EAAT & excitatory amino-acid transporters \\
\hline EAD & early Alzheimer disease \\
\hline EF-Tu & elongation factor $\mathrm{Tu}$ \\
\hline ENO1 & $\alpha$-enolase \\
\hline ER & endoplasmic reticulum \\
\hline FBA-C & fructose bisphosphate aldolase $\mathrm{C}$ \\
\hline GAPDH & glyceraldehyde-3-phosphate dehydrogenase \\
\hline GDH & glutamate dehydrogenase \\
\hline GFAP & glial fibrillary acidic protein \\
\hline GGS & gamma-glutamyl semialdehyde ALS \\
\hline GNBP & guanine nucleotide-binding protein \\
\hline GRP & glucose regulated protein \\
\hline GS & glutamine synthase \\
\hline GST & glutathione- $S$-transferase \\
\hline HAS & irreversibly oxidized albumin \\
\hline $\mathrm{HD}$ & Huntington disease \\
\hline HNE & 4-hydroxy-2-trans-nonenal \\
\hline Hp & haptoglobin \\
\hline HPG & homopropargylglycin \\
\hline HSA & human serum albumin \\
\hline HSC 71 & heat shock cognate 71 \\
\hline HSP & heat shock protein \\
\hline ICAT & isotope coded affinity tag \\
\hline IDH & isocitrate dehydrogease \\
\hline IR & ischemia reperfusion \\
\hline $\mathrm{LDH}$ & lactate dehydrogenase \\
\hline MAPKI & mitogen-activated protein kinase I \\
\hline MDA & malondialdehyde \\
\hline $\mathrm{MDH}$ & malate dehydrogenase \\
\hline MnSOD & manganese superoxide dismutase \\
\hline MRP & multidrug resistant protein \\
\hline MS & mass spectrometry \\
\hline
\end{tabular}

$\begin{array}{ll}\text { NEM } & \text { N-ethylmaleimide } \\ \text { NO } & \text { nitric oxide } \\ \text { OS } & \text { oxidative stress } \\ \text { PCAD } & \text { pre clinical Alzheimer disease } \\ \text { PCO } & \text { protein carbonyl } \\ \text { PD } & \text { Parkinson disease } \\ \text { PDH } & \text { pyruvate dehydrogenase } \\ \text { PEBP } & \text { phosphatidylethanolamine-binding protein } \\ \text { PGK } & \text { phosphoglycerate kinase } \\ \text { PGM } & \text { phosphoglycerate mutase } \\ \text { Pin1 } & \text { peptidyl prolyl cis-trans isomerase } \\ \text { PK } & \text { pyruvate kinase } \\ \text { PMF } & \text { peptide mass fingerprinting } \\ \text { PROP } & \text { purification of reversibly oxidized proteins } \\ \text { PRX } & \text { peroxiredoxin } \\ \text { PSNO } & \text { S-nitrosylated proteins } \\ \text { PTM } & \text { post-translational modifications } \\ \text { RAC } & \text { resin-assisted capture } \\ \text { RBP } & \text { retinol-binding protein } \\ \text { RNS } & \text { reactive nitrogen species } \\ \text { ROS } & \text { reactive oxygen species } \\ \text { SBP1 } & \text { syntaxin binding protein I } \\ \text { SERCA2a } & \text { sarco(endo)plasmic reticulum Ca }{ }^{2+} \text {-ATPase } \\ \text { SIL } & \text { stable isotope labeling } \\ \text { SPH } & \text { solid-phase hydrazide } \\ \text { TBARS } & \text { thiobarbituric acid-reactive substances } \\ \text { TCTP } & \text { translationally controlled tumor protein } \\ \text { TMT } & \text { tandem mass tag } \\ \text { TPI } & \text { triose phosphate isomerase } \\ \text { UCH } & \text { ubiquitin carboxy-terminal hydrolase } \\ \text { V-ATP } & \text { vacuolar-ATPase } \\ \text { VDAC } & \text { voltage-dependent anion channel } \\ \gamma \text {-SNAP } & \text { soluble } N \text {-ethylmaleimide-sensitive factor at- } \\ & \text { tachment protein } \gamma \\ & \end{array}$

\section{REFERENCES}

Abe K, Pan LH, Watanabe M, Kato T, Itoyama Y. 1995. Induction of nitrotyrosine-like immunoreactivity in the lower motor-neuron of amyotrophic-lateral-sclerosis. Neurosci Lett 199:152-154.

Abello N, Barroso B, Kerstjens HA, Postma DS, Bischoff R. 2010. Chemical labeling and enrichment of nitrotyrosine-containing peptides. Talanta 80:1503-1512.

Alam ZI, Jenner A, Daniel SE, Lees AJ, Cairns N, Marsden CD, Jenner P, Halliwell B. 1997. Oxidative DNA damage in the Parkinsonian brain: An apparent selective increase in 8-hydroxyguanine levels in substantia nigra. J Neurochem 69:1196-1203.

Aluise CD, Robinson RA, Cai J, Pierce WM, Markesbery WR, Butterfield DA. 2011. Redox proteomics analysis of brains from subjects with amnestic mild cognitive impairment compared to brains from subjects with preclinical Alzheimer's disease: Insights into memory loss in MCI. J Alzheimers Dis 23:257-269.

Amblard F, Cho JH, Schinazi RF. 2009. Cu(I)-catalyzed Huisgen azidealkyne 1,3-dipolar cycloaddition reaction in nucleoside, nucleotide, and oligonucleotide chemistry. Chem Rev 109:4207-4220.

Andersen PM. 2000. Genetic factors in the early diagnosis of ALS. Amyotroph Lateral Scler Other Motor Neuron Disord 1(Suppl. 1):S31S42.

Andreassen OA, Dedeoglu A, Ferrante RJ, Jenkins BG, Ferrante KL, Thomas M, Friedlich A, Browne SE, Schilling G, Borchelt DR, Hersch SM, Ross CA, Beal MF. 2001. Creatine increase survival and delays motor symptoms in a transgenic animal model of Huntington's disease. Neurobiol Dis 8:479-491. 
Andreoli R, Manini P, Corradi M, Mutti A, Niessen WM. 2003. Determination of patterns of biologically relevant aldehydes in exhaled breath condensate of healthy subjects by liquid chromatography/atmospheric chemical ionization tandem mass spectrometry. Rapid Commun Mass Spectrom 17:637-645.

Arbuzova S, Hutchin T, Cuckle H. 2002. Mitochondrial dysfunction and Down's syndrome. BioEssays 24:681-684.

Barjaktarovic Z, Schmaltz D, Shyla A, Azimzadeh O, Schulz S, Haagen J, Dorr W, Sarioglu H, Schafer A, Atkinson MJ, Zischka H, Tapio S. 2011. Radiation-induced signaling results in mitochondrial impairment in mouse heart at 4 weeks after exposure to X-rays. PLoS ONE 6: e27811.

Baynes JW. 1991. Role of oxidative stress in development of complications in diabetes. Diabetes 40:405-412.

Beal MF, Ferrante RJ. 2004. Experimental therapeutics in transgenic mouse models of Huntington's disease. Nat Rev Neurosci 5:373-384.

Behl C. 1997. Amyloid beta-protein toxicity and oxidative stress in Alzheimer's disease. Cell Tissue Res 290:471-480.

Berlett BS, Stadtman ER. 1997. Protein oxidation in aging, disease, and oxidative stress. J Biol Chem 272:20313-20316.

Bollineni RC, Fedorova M, Hoffmann R. 2011. Identification of carbonylated peptides by tandem mass spectrometry using a precursor ion-like scan in negative ion mode. J Proteomics 74:23512359.

Boyd-Kimball D, Castegna A, Sultana R, Poon HF, Petroze R, Lynn BC, Klein JB, Butterfield DA. 2005. Proteomic identification of proteins oxidized by Abeta(1-42) in synaptosomes: Implications for Alzheimer's disease. Brain Res 1044:206-215.

Boyd-Kimball D, Poon HF, Lynn BC, Cai J, Pierce WM, Jr., Klein JB, Ferguson J, Link CD, Butterfield DA. 2006. Proteomic identification of proteins specifically oxidized in Caenorhabditis elegans expressing human Abeta(1-42): Implications for Alzheimer's disease. Neurobiol Aging 27:1239-1249.

Brioschi M, Polvani G, Fratto P, Parolari A, Agostoni P, Tremoli E, Banfi C. 2012. Redox proteomics identification of oxidatively modified myocardial proteins in human heart failure: Implications for protein function. PLoS ONE 7:e35841.

Butterfield DA. 2006. Oxidative stress in neurodegenerative disorders. Antioxid Redox Signal 8:1971-1973.

Butterfield DA, Kanski J. 2001. Brain protein oxidation in age-related neurodegenerative disorders that are associated with aggregated proteins. Mech Ageing Dev 122:945-962.

Butterfield DA, Lauderback CM. 2002. Lipid peroxidation and protein oxidation in Alzheimer's disease brain: Potential causes and consequences involving amyloid beta-peptide-associated free radical oxidative stress. Free Radic Biol Med 32:1050-1060.

Butterfield DA, Stadtman ER. 1997. Protein Oxidation processes in aging brain. Adv Cell Aging Gerontol 2:161-191.

Butterfield DA, Sultana R. 2007. Redox proteomics identification of oxidatively modified brain proteins in Alzheimer's disease and mild cognitive impairment: Insights into the progression of this dementing disorder. J Alzheimers Dis 12:61-72.

Butterfield DA, Sultana R. 2008. Redox proteomics: Understanding oxidative stress in the progression of age-related neurodegenerative disorders. Expert Rev Proteomics 5:157-160.

Butterfield DA, Abdul HM, Newman S, Reed T. 2006a. Redox proteomics in some age-related neurodegenerative disorders or models thereof. NeuroRx 3:344-357.

Butterfield DA, Abdul HM, Opii W, Newman SF, Joshi G, Ansari MA, Sultana R. 2006b. Pin1 in Alzheimer's disease. J Neurochem 98:16971706.

Butterfield DA, Galvan V, Lange MB, Tang H, Sowell RA, Spilman P, Fombonne J, Gorostiza O, Zhang J, Sultana R, Bredesen DE. 2010. In vivo oxidative stress in brain of Alzheimer disease transgenic mice: Requirement for methionine 35 in amyloid beta-peptide of APP. Free Radic Biol Med 48:136-144.
Butterfield DA, Perluigi M, Reed T, Muharib T, Hughes CP, Robinson RA, Sultana R. 2012. Redox proteomics in selected neurodegenerative disorders: From its infancy to future applications. Antioxid Redox Signal 17:1610-1655.

Carney JM, Starke-Reed PE, Oliver CN, Landum RW, Cheng MS, Wu JF, Floyd RA. 1991. Reversal of age-related increase in brain protein oxidation, decrease in enzyme activity, and loss in temporal and spatial memory by chronic administration of the spin-trapping compound $\mathrm{N}$ tert-butyl-alpha-phenylnitrone. Proc Natl Acad Sci USA 88:36333636.

Casoni F, Basso M, Massignan T, Gianazza E, Cheroni C, Salmona M, Bendotti C, Bonetto V. 2005. Protein nitration in a mouse model of familial amyotrophic lateral sclerosis: Possible multifunctional role in the pathogenesis. J Biol Chem 280:16295-16304.

Castegna A, Aksenov M, Aksenova M, Thongboonkerd V, Klein JB, Pierce WM, Booze R, Markesbery WR, Butterfield DA. 2002a. Proteomic identification of oxidatively modified proteins in Alzheimer's disease brain. Part I: Creatine kinase BB, glutamine synthase, and ubiquitin carboxy-terminal hydrolase L-1. Free Radic Biol Med 33:562-571.

Castegna A, Aksenov M, Thongboonkerd V, Klein JB, Pierce WM, Booze R, Markesbery WR, Butterfield DA. 2002b. Proteomic identification of oxidatively modified proteins in Alzheimer's disease brain. Part II: Dihydropyrimidinase-related protein 2, alpha-enolase and heat shock cognate 71. J Neurochem 82:1524-1532.

Castegna A, Thongboonkerd V, Klein JB, Lynn B, Markesbery WR, Butterfield DA. 2003. Proteomic identification of nitrated proteins in Alzheimer's disease brain. J Neurochem 85:1394-1401.

Cenini G, Dowling ALS, Beckett TL, Barone E, Mancuso C, Murphy MP, LeVine H, Lott IT, Schmitt FA, Butterfield DA, Head E. 2012. Association between frontal cortex oxidative damage and beta-amyloid as a function of age in Down syndrome. Biochim Biophys Acta 1822:130-138.

Chavez J, Wu J, Han B, Chung WG, Maier CS. 2006. New role for an old probe: Affinity labeling of oxylipid protein conjugates by N'-aminooxymethylcarbonylhydrazino D-biotin. Anal Chem 78:6847-6854.

Chavez JD, Bisson WH, Maier CS. 2010. A targeted mass spectrometrybased approach for the identification and characterization of proteins containing alpha-aminoadipic and gamma-glutamic semialdehyde residues. Anal Bioanal Chem 398:2905-2914.

Chiappetta G, Corbo C, Palmese A, Galli F, Piroddi M, Marino G, Amoresano A. 2009. Quantitative identification of protein nitration sites. Proteomics 9:1524-1537.

Choi J, Malakowsky CA, Talent JM, Conrad CC, Gracy RW. 2002. Identification of oxidized plasma proteins in Alzheimer's disease. Biochem Biophys Res Commun 293:1566-1570.

Cini M, Moretti A. 1995. Studies on lipid peroxidation and protein oxidation in the aging brain. Neurobiol Aging 16:53-57.

Cleveland DW, Rothstein JD. 2001. From Charcot to Lou Gehrig: Deciphering selective motor neuron death in ALS. Nat Rev Neurosci 2:806819.

Cocciolo A, Di Domenico F, Coccia R, Fiorini A, Cai J, Pierce WM, Mecocci P, Butterfield DA, Perluigi M. 2012. Decreased expression and increased oxidation of plasma haptoglobin in Alzheimer disease: Insights from redox proteomics. Free Radic Biol Med 53:1868-1876.

Codreanu SG, Kim HY, Porter NA, Liebler DC. 2012. Biotinylated probes for the analysis of protein modification by electrophiles. Methods Mol Biol 803:77-95.

Cross CE, Halliwell B, Borish ET, Pryor WA, Ames BN, Saul RL, McCord JM, Harman D. 1987. Oxygen radicals and human disease. Ann Intern Med 107:526-545.

Dachsel JC, Farrer MJ. 2010. LRRK2 and Parkinson disease. Arch Neurol 67:542-547.

D'Alessandro A, Rinalducci S, Zolla L. 2011. Redox proteomics and drug development. J Proteomics 74:2575-2595.

Dalle-Donne I. 2007. Familial amyotrophic lateral sclerosis (FALS): Emerging hints from redox proteomics. Highlight commentary on: 
"Redox proteomics analysis of oxidatively modified proteins in G93ASOD1 transgenic mice-A model of familial amyotrophic lateral sclerosis" Free Radic Biol Med 43:157-159.

Dalle-Donne I, Aldini G, Carini M, Colombo R, Rossi R, Milzani A. 2006a. Protein carbonylation, cellular dysfunction, and disease progression. $\mathrm{J}$ Cell Mol Med 10:389-406.

Dalle-Donne I, Rossi R, Colombo R, Giustarini D, Milzani A. 2006b. Biomarkers of oxidative damage in human disease. Clin Chem 52:601623.

Dalle-Donne I, Scaloni A, Butterfield DA. 2006. Redox proteomics: From protein modification to cellular dysfunction and diseases. Hoboken, NJ: John Wiley \& Sons.

Dalle-Donne I, Rossi R, Giustarini D, Colombo R, Milzani A. 2007. Sglutathionylation in protein redox regulation. Free Radic Biol Med 43:883-898.

Dalle-Donne I, Carini M, Orioli M, Vistoli G, Regazzoni L, Colombo G, Rossi R, Milzani A, Aldini G. 2009. Protein carbonylation: 2,4Dinitrophenylhydrazine reacts with both aldehydes/ketones and sulfenic acids. Free Radic Biol Med 46:1411-1419.

Di Domenico F, Coccia R, Butterfield DA, Perluigi M. 2011. Circulating biomarkers of protein oxidation for Alzheimer disease: Expectations within limits. Biochim Biophys Acta 1814:1785-1795.

Di Domenico F, Sultana R, Ferree A, Smith K, Barone E, Perluigi M, Coccia R, Pierce W, Cai J, Mancuso C, Squillace R, Wiengele M, Dalle-Donne I, Wolozin B, Butterfield DA. 2012. Redox proteomics analyses of the influence of co-expression of wild-type or mutated LRRK2 and Tau on $C$. elegans protein expression and oxidative modification: Relevance to Parkinson disease. Antioxid Redox Signal 17:1490-506.

Dogru-Abbasoglu S, Tamer-Toptani S, Ugurnal B, Kocak-Toker N, AykacToker G, Uysal M. 1997. Lipid peroxidation and antioxidant enzymes in livers and brains of aged rats. Mech Ageing Dev 98:177-180.

Dominguez C, Ruiz E, Gussinye M, Carrascosa A. 1998. Oxidative stress at onset and in early stages of type 1 diabetes in children and adolescents. Diabetes Care 21:1736-1742.

Eng J, McCormack A, Yates J. 1994. An approach to correlate tandem mass spectral data of peptides with amino acid sequences in a protein database. J Am Soc Mass Spectrom 5:976-989.

Esterbauer H, Cheeseman KH. 1990. Determination of aldehydic lipid peroxidation products: Malonaldehyde and 4-hydroxynonenal. Methods Enzymol 186:407-421.

Esterbauer H, Schaur RJ, Zollner H. 1991. Chemistry and biochemistry of 4hydroxynonenal, malonaldehyde and related aldehydes. Free Radic Biol Med 11:81-128.

Ferrante RJ, Browne SE, Shinobu LA, Bowling AC, Baik MJ, MacGarvey U, Kowall NW, Brown RH, Beal MF. 1997. Evidence of increased oxidative damage in both sporadic and familial amyotrophic lateral sclerosis. J Neurochem 69:2064-2074.

Ferrer I, Martinez A, Blanco R, Dalfo E, Carmona M. 2011. Neuropathology of sporadic Parkinson disease before the appearance of Parkinsonism: Preclinical Parkinson disease. J Neural Transm 118:821-839.

Fitzmaurice PS, Shaw IC, Kleiner HE, Miller RT, Monks TJ, Lau SS, Mitchell JD, Lynch PG. 1996. Evidence for DNA damage in amyotrophic lateral sclerosis. Muscle Nerve 19:797-798.

Floor E, Wetzel MG. 1998. Increased protein oxidation in human substantia nigra pars compacta in comparison with basal ganglia and prefrontal cortex measured with an improved dinitrophenylhydrazine assay. J Neurochem 70:268-275.

Fu C, Hu J, Liu T, Ago T, Sadoshima J, Li H. 2008. Quantitative analysis of redox-sensitive proteome with DIGE and ICAT. J Proteome Res 7:3789-3802.

Gao XH, Bedhomme M, Veyel D, Zaffagnini M, Lemaire SD. 2009. Methods for analysis of protein glutathionylation and their application to photosynthetic organisms. Mol Plant 2:218-235.

Gharbi S, Gaffney P, Yang A, Zvelebil MJ, Cramer R, Waterfield MD, Timms JF. 2002. Evaluation of two-dimensional differential gel electrophoresis for proteomic expression analysis of a model breast cancer cell system. Mol Cell Proteomics 1:91-98.

Ghezzi P, Bonetto V. 2003. Redox proteomics: Identification of oxidatively modified proteins. Proteomics 3:1145-1153.

Giustarini D, Rossi R, Milzani A, Colombo R, Dalle-Donne I. 2004. Sglutathionylation: From redox regulation of protein functions to human diseases. J Cell Mol Med 8:201-212.

Grune T, Reinheckel T, Davies KJ. 1997. Degradation of oxidized proteins in mammalian cells. FASEB J 11:526-534.

Gurney ME. 1997. The use of transgenic mouse models of amyotrophic lateral sclerosis in preclinical drug studies. J Neurol Sci 152:S67-S73.

Hahne H, Neubert P, Kuhn K, Etienne C, Bomgarden R, Rogers JC, Kuster B. 2012. Carbonyl-reactive tandem mass tags for the proteome-wide quantification of N-linked glycans. Anal Chem 84:3716-3724.

Hang HC, Wilson JP, Charron G. 2011. Bioorthogonal chemical reporters for analyzing protein lipidation and lipid trafficking. Acc Chem Res 44:699-708.

Haudek VJ, Gundacker NC, Slany A, Wimmer H, Bayer E, Pable K, Gerner C. 2008. Consequences of acute and chronic oxidative stress upon the expression pattern of proteins in peripheral blood mononuclear cells. $\mathbf{J}$ Proteome Res 7:5138-5147.

Hoeldtke RD, Bryner KD, McNeill DR, Hobbs GR, Riggs JE, Warehime SS, Christie I, Ganser G, Van Dyke K. 2002. Nitrosative stress, uric acid, and peripheral nerve function in early type 1 diabetes. Diabetes 51:2817-2825.

Iannello RC, Crack PJ, de Haan JB, Kola I. 1999. Oxidative stress and neural dysfunction in Down syndrome. J Neural Transm Suppl 57:257-267.

Irazusta V, Moreno-Cermeno A, Cabiscol E, Tamarit J, Ros J. 2010. Proteomic strategies for the analysis of carbonyl groups on proteins. Curr Protein Pept Sci 11:652-658.

Ishihara K, Amano K, Takaki E, Ebrahim AS, Shimohata A, Shibazaki N, Inoue I, Takaki M, Ueda Y, Sago H, Epstein CJ, Yamakawa K. 2009. Increased lipid peroxidation in Down's syndrome mouse models. J Neurochem 110:1965-1976.

Jacobs AT, Marnett LJ. 2010. Systems analysis of protein modification and cellular responses induced by electrophile stress. Acc Chem Res 43:673-683.

Jaffrey SR, Erdjument-Bromage H, Ferris CD, Tempst P, Snyder SH. 2001. Protein S-nitrosylation: A physiological signal for neuronal nitric oxide. Nat Cell Biol 3:193-197.

Josefsen K, Nielsen SM, Campos A, Seifert T, Hasholt L, Nielsen JE, Norremolle A, Skotte NH, Secher NH, Quistorff B. 2010. Reduced gluconeogenesis and lactate clearance in Huntington's disease. Neurobiol Dis 40:656-662.

Jovanovic SV, Clements D, MacLeod K. 1998. Biomarkers of oxidative stress are significantly elevated in Down syndrome. Free Radic Biol Med 25:1044-1048.

Junn E, Mouradian MM. 2002. Human alpha-synuclein over-expression increases intracellular reactive oxygen species levels and susceptibility to dopamine. Neurosci Lett 320:146-150.

Kanski J, Behring A, Pelling J, Schoneich C. 2005. Proteomic identification of 3-nitrotyrosine-containing rat cardiac proteins: Effects of biological aging. Am J Physiol Heart Circ Physiol 288:H371-381.

Keller JN, Hanni KB, Markesbery WR. 2000a. Impaired proteasome function in Alzheimer's disease. J Neurochem 75:436-439.

Keller JN, Hanni KB, Markesbery WR. 2000b. Possible involvement of proteasome inhibition in aging: Implications for oxidative stress. Mech Ageing Dev 113:61-70.

Kim H, Eliuk S, Deshane J, Meleth S, Sanderson T, Pinner A, Robinson G, Wilson L, Kirk M, Barnes S. 2007. 2D gel proteomics: An approach to study age-related differences in protein abundance or isoform complexity in biological samples. Methods Mol Biol 371:349-391.

Kim HY, Tallman KA, Liebler DC, Porter NA. 2009. An azido-biotin reagent for use in the isolation of protein adducts of lipid-derived electrophiles by streptavidin catch and photorelease. Mol Cell Proteomics 8:20802089. 
Kohr MJ, Sun J, Aponte A, Wang G, Gucek M, Murphy E, Steenbergen C. 2011. Simultaneous measurement of protein oxidation and S-nitrosylation during preconditioning and ischemia/reperfusion injury with resin-assisted capture. Circ Res 108:418-426.

Korchazhkina O, Exley C, Andrew Spencer S. 2003. Measurement by reversed-phase high-performance liquid chromatography of malondialdehyde in normal human urine following derivatisation with 2,4dinitrophenylhydrazine. J Chromatogr B Analyt Technol Biomed Life Sci 794:353-362.

Korolainen MA, Pirttila T. 2009. Cerebrospinal fluid, serum and plasma protein oxidation in Alzheimer's disease. Acta Neurol Scand 119:3238.

Korolainen MA, Goldsteins G, Nyman TA, Alafuzoff I, Koistinaho J, Pirttila T. 2006. Oxidative modification of proteins in the frontal cortex of Alzheimer's disease brain. Neurobiol Aging 27:42-53.

Korolainen MA, Nyman TA, Nyyssonen P, Hartikainen ES, Pirttila T. 2007. Multiplexed proteomic analysis of oxidation and concentrations of cerebrospinal fluid proteins in Alzheimer disease. Clin Chem 53:657-665.

Kremer B, Weber B, Hayden MR. 1992. New insights into the clinicalfeatures, pathogenesis and molecular-genetics of Huntington disease. Brain Pathol 2:321-335.

Kumar V, Calamaras TD, Haeussler D, Colucci WS, Cohen RA, McComb ME, Pimentel D, Bachschmid MM. 2012. Cardiovascular redox and ox stress proteomics. Antioxid Redox Signal 17:1528-1559.

Kurien BT, Dorri Y, Dillon S, Dsouza A, Scofield RH. 2011. An overview of Western blotting for determining antibody specificities for immunohistochemistry. Methods Mol Biol 717:55-67.

Lallana E, Riguera R, Fernandez-Megia E. 2011. Reliable and efficient procedures for the conjugation of biomolecules through Huisgen azide-alkyne cycloadditions. Angew Chem Int Ed Engl 50:8794-8804.

Li JY, Popovic N, Brundin P. 2005. The use of the R6 transgenic mouse models of Huntington's disease in attempts to develop novel therapeutic strategies. NeuroRx 2:447-464.

Linares Ma, Marín-García P, Méndez Do, Puyet A, Diez A, Bautista JM. 2011. Proteomic approaches to identifying carbonylated proteins in brain tissue. J Proteome Res 10:1719-1727.

Lindemann C, Leichert LI. 2012. Quantitative redox proteomics: The NOxICAT method. Methods Mol Biol 893:387-403.

Madian AG, Regnier FE. 2010a. Profiling carbonylated proteins in human plasma. J Proteome Res 9:1330-1343.

Madian AG, Regnier FE. 2010b. Proteomic identification of carbonylated proteins and their oxidation sites. J Proteome Res 9:3766-3780.

Madian AG, Diaz-Maldonado N, Gao Q, Regnier FE. 2011a. Oxidative stress induced carbonylation in human plasma. J Proteomics 74:23962416.

Madian AG, Myracle AD, Diaz-Maldonado N, Rochelle NS, Janle EM, Regnier FE. 2011b. Differential carbonylation of proteins as a function of in vivo oxidative stress. J Proteome Res 10:3959-3972.

Marin-Corral J, Fontes CC, Pascual-Guardia S, Sanchez F, Olivan M, Argiles JM, Busquets S, Lopez-Soriano FJ, Barreiro E. 2010. Redox balance and carbonylated proteins in limb and heart muscles of cachectic rats. Antioxid Redox Signal 12:365-380.

Markesbery WR. 1997. Oxidative stress hypothesis in Alzheimer's disease. Free Radic Biol Med 23:134-147.

Markesbery WR, Lovell MA. 1998. Four-hydroxynonenal, a product of lipid peroxidation, is increased in the brain in Alzheimer's disease. Neurobiol Aging 19:33-36.

Martinez-Acedo P, Nunez E, Sanchez-Gomez FJ, Moreno M, Ramos E, Izquierdo-Alvarez A, Miro-Casas E, Mesa R, Rodriguez P, MartinezRuiz A, Garcia-Dorado D, Lamas S, Vazquez J. 2012. GELSILOX: A novel strategy for global analysis of the dynamic thiol redox proteome. Mol Cell Proteomics 11:800-813.

Matsuyama Y, Terawaki H, Terada T, Era S. 2009. Albumin thiol oxidation and serum protein carbonyl formation are progressively enhanced with advancing stages of chronic kidney disease. Clin Exp Nephrol 13:308315.
Mecocci P, MacGarvey U, Beal MF. 1994. Oxidative damage to mitochondrial DNA is increased in Alzheimer's disease. Ann Neurol 36:747751.

Mirzaei H, Regnier F. 2005. Affinity chromatographic selection of carbonylated proteins followed by identification of oxidation sites using tandem mass spectrometry. Anal Chem 77:2386-2392.

Mirzaei H, Baena B, Barbas C, Regnier F. 2008. Identification of oxidized proteins in rat plasma using avidin chromatography and tandem mass spectrometry. Proteomics 8:1516-1527.

Mitrogianni Z, Barbouti A, Galaris D, Siamopoulos KC. 2004. Tyrosine nitration in plasma proteins from patients undergoing hemodialysis. Am J Kidney Dis 44:286-292.

Miyamoto M. 1997. Characteristics of age-related behavioral changes in senescence-accelerated mouse SAMP8 and SAMP10. Exp Gerontol 32:139-148.

Munch G, Keis R, Wessels A, Riederer P, Bahner U, Heidland A, Niwa T, Lemke HD, Schinzel R. 1997. Determination of advanced glycation end products in serum by fluorescence spectroscopy and competitive ELISA. Eur J Clin Chem Clin Biochem 35:669-677.

Nagy K, Pollreisz F, Takats Z, Vekey K. 2004. Atmospheric pressure chemical ionization mass spectrometry of aldehydes in biological matrices. Rapid Commun Mass Spectrom 18:2473-2478.

Newman SF, Sultana R, Perluigi M, Coccia R, Cai J, Pierce WM, Klein JB, Turner DM, Butterfield DA. 2007. An increase in S-glutathionylated proteins in the Alzheimer's disease inferior parietal lobule, a proteomics approach. J Neurosci Res 85:1506-1514.

Niwa T, Naito C, Mawjood AH, Imai K. 2000. Increased glutathionyl hemoglobin in diabetes mellitus and hyperlipidemia demonstrated by liquid chromatography/electrospray ionization-mass spectrometry. Clin Chem 46:82-88.

Nunomura A, Perry G, Pappolla MA, Friedland RP, Hirai K, Chiba S, Smith MA. 2000. Neuronal oxidative stress precedes amyloid-beta deposition in Down syndrome. J Neuropathol Exp Neurol 59:1011-1017.

Odetti P, Angelini G, Dapino D, Zaccheo D, Garibaldi S, Dagna-Bricarelli F, Piombo G, Perry G, Smith M, Traverso N, Tabaton M. 1998. Early glycoxidation damage in brains from Down's syndrome. Biochem Biophys Res Commun 243:849-851.

Oh-Ishi M, Ueno T, Maeda T. 2003. Proteomic method detects oxidatively induced protein carbonyls in muscles of a diabetes model Otsuka Long-Evans Tokushima Fatty (OLETF) rat. Free Radic Biol Med 34:11-22.

Oliver CN, Starke-Reed PE, Stadtman ER, Liu GJ, Carney JM, Floyd RA. 1990. Oxidative damage to brain proteins, loss of glutamine synthetase activity, and production of free radicals during ischemia/reperfusioninduced injury to gerbil brain. Proc Natl Acad Sci USA 87:5144-5147.

Osterman IA, Ustinov AV, Evdokimov DV, Korshun VA, Sergiev PV, Serebryakova MV, Demina IA, Galyamina MA, Govorun VM, Dontsova OA. 2012. Nascent proteome study by combination of click chemistry and 2D gel electrophoresis. Proteomics 13(1):17-21.

Ostrerova-Golts N, Petrucelli L, Hardy J, Lee JM, Farer M, Wolozin B. 2000. The A53T alpha-synuclein mutation increases iron-dependent aggregation and toxicity. J Neurosci 20:6048-6054.

Palmese A, De Rosa C, Marino G, Amoresano A. 2011. Dansyl labeling and bidimensional mass spectrometry to investigate protein carbonylation. Rapid Commun Mass Spectrom 25:223-231.

Perez-De La Cruz V, Santamaria A. 2007. Integrative hypothesis for Huntington's disease: A brief review of experimental evidence. Physiol Res 56:513-526.

Perkins DN, Pappin DJ, Creasy DM, Cottrell JS. 1999. Probability-based protein identification by searching sequence databases using mass spectrometry data. Electrophoresis 20:3551-3567.

Perluigi M, Butterfield DA. 2012. Oxidative stress and Down syndrome: A route toward Alzheimer-like dementia. Curr Gerontol Geriatr Res 2012:724904.

Perluigi M, Fai Poon H, Hensley K, Pierce WM, Klein JB, Calabrese V, De Marco C, Butterfield DA. 2005a. Proteomic analysis of 4-hydroxy-2- 
nonenal-modified proteins in G93A-SOD1 transgenic mice-A model of familial amyotrophic lateral sclerosis. Free Radic Biol Med 38:960968.

Perluigi M, Poon HF, Maragos W, Pierce WM, Klein JB, Calabrese V, Cini C, De Marco C, Butterfield DA. 2005b. Proteomic analysis of protein expression and oxidative modification in $\mathrm{r} 6 / 2$ transgenic mice: A model of Huntington disease. Mol Cell Proteomics 4:1849-1861.

Perluigi M, Sultana R, Cenini G, Di Domenico F, Memo M, Pierce WM, Coccia R, Butterfield DA. 2009. Redox proteomics identification of 4hydroxynonenal-modified brain proteins in Alzheimer's disease: Role of lipid peroxidation in Alzheimer's disease pathogenesis. Proteomics Clin Appl 3:682-693.

Perluigi M, Di Domenico F, Blarzino C, Foppoli C, Cini C, Giorgi A, Grillo C, De Marco F, Butterfield DA, Schinina ME, Coccia R. 2010a. Effects of UVB-induced oxidative stress on protein expression and specific protein oxidation in normal human epithelial keratinocytes: A proteomic approach. Proteome Sci 8:13.

Perluigi M, Di Domenico F, Giorgi A, Schinina ME, Coccia R, Cini C, Bellia F, Cambria MT, Cornelius C, Butterfield DA, Calabrese V. 2010b. Redox proteomics in aging rat brain: Involvement of mitochondrial reduced glutathione status and mitochondrial protein oxidation in the aging process. J Neurosci Res 88:3498-3507.

Perluigi M, di Domenico F, Fiorini A, Cocciolo A, Giorgi A, Foppoli C, Butterfield DA, Giorlandino M, Giorlandino C, Schinina ME, Coccia R. 2011. Oxidative stress occurs early in Down syndrome pregnancy: A redox proteomics analysis of amniotic fluid. Proteomics Clin Appl 5:167-178.

Petropoulos I, Conconi M, Wang X, Hoenel B, Bregegere F, Milner Y, Friguet B. 2000. Increase of oxidatively modified protein is associated with a decrease of proteasome activity and content in aging epidermal cells. J Gerontol A Biol Sci Med Sci 55:B220-B227.

Pignatelli B, Li CQ, Boffetta P, Chen Q, Ahrens W, Nyberg F, Mukeria A, Bruske-Hohlfeld I, Fortes C, Constantinescu V, Ischiropoulos H, Ohshima H. 2001. Nitrated and oxidized plasma proteins in smokers and lung cancer patients. Cancer Res 61:778-784.

Piroddi M, Palmese A, Pilolli F, Amoresano A, Pucci P, Ronco C, Galli F. 2011. Plasma nitroproteome of kidney disease patients. Amino Acids 40:653-667.

Plowey ED, Cherra SJ III, Liu YJ, Chu CT. 2008. Role of autophagy in G2019S-LRRK2-associated neurite shortening in differentiated SHSY5Y cells. J Neurochem 105:1048-1056.

Poon HF, Calabrese V, Calvani M, Butterfield DA. 2006a "Proteomics analyses of specific protein oxidation and protein expression in aged rat brain and its modulation by L-acetylcarnitine: insights into the mechanisms of action of this proposed therapeutic agent for CNS disorders associated with oxidative stress." Antioxid Redox Signal 8:381-394.

Poon HF, Shepherd HM, Reed TT, Calabrese V, Stella AM, Pennisi G, Cai J, Pierce WM, Klein JB, Butterfield DA. 2006b. Proteomics analysis provides insight into caloric restriction mediated oxidation and expression of brain proteins associated with age-related impaired cellular processes: Mitochondrial dysfunction, glutamate dysregulation and impaired protein synthesis. Neurobiol Aging 27:1020-1034.

Poon HF, Castegna A, Farr SA, Thongboonkerd V, Lynn BC, Banks WA, Morley JE, Klein JB, Butterfield DA. 2004. Quantitative proteomics analysis of specific protein expression and oxidative modification in aged senescence-accelerated-prone 8 mice brain. Neuroscience 126:915-926.

Poon HF, Farr SA, Banks WA, Pierce WM, Klein JB, Morley JE, Butterfield DA. 2005a. Proteomic identification of less oxidized brain proteins in aged senescence-accelerated mice following administration of antisense oligonucleotide directed at the A beta region of amyloid precursor protein. Mol Brain Res 138:8-16.

Poon HF, Frasier M, Shreve N, Calabrese V, Wolozin B, Butterfield DA. 2005b. Mitochondrial associated metabolic proteins are selectively oxidized in A30P alpha-synuclein transgenic mice-A model of familial Parkinson's disease. Neurobiol Dis 18:492-498.
Poon HF, Hensley K, Thongboonkerd V, Merchant ML, Lynn BC, Pierce WM, Klein JB, Calabrese V, Butterfield DA. 2005c. Redox proteomics analysis of oxidatively modified proteins in G93A-SOD1 transgenic mice-A model of familial amyotrophic lateral sclerosis. Free Radic Biol Med 39:453-462.

Poon HF, Vaishnav RA, Butterfield DA, Getchell ML, Getchell TV. 2005d. Proteomic identification of differentially expressed proteins in the aging murine olfactory system and transcriptional analysis of the associated genes. J Neurochem 94:380-392.

Rauniyar N, Prokai L. 2011. Isotope-coded dimethyl tagging for differential quantification of posttranslational protein carbonylation by 4-hydroxy2-nonenal, an end-product of lipid peroxidation. J Mass Spectrom 46:976-985.

Rauniyar N, Prokai-Tatrai K, Prokai L. 2010. Identification of carbonylation sites in apomyoglobin after exposure to 4-hydroxy-2-nonenal by solidphase enrichment and liquid chromatography-electrospray ionization tandem mass spectrometry. J Mass Spectrom 45:398-410.

Reed TT. 2011. Lipid peroxidation and neurodegenerative disease. Free Radic Biol Med 51:1302-1319.

Reed T, Perluigi M, Sultana R, Pierce WM, Klein JB, Turner DM, Coccia R, Markesbery WR, Butterfield DA. 2008. Redox proteomic identification of 4-hydroxy-2-nonenal-modified brain proteins in amnestic mild cognitive impairment: insight into the role of lipid peroxidation in the progression and pathogenesis of Alzheimer's disease. Neurobiol Dis 30:107-120.

Reed TT, Pierce WM, Jr., Turner DM, Markesbery WR, Butterfield DA. 2009a. Proteomic identification of nitrated brain proteins in early Alzheimer's disease inferior parietal lobule. J Cell Mol Med 13:20192029.

Reed TT, Pierce WM, Markesbery WR, Butterfield DA. 2009b. Proteomic identification of HNE-bound proteins in early Alzheimer disease: Insights into the role of lipid peroxidation in the progression of AD. Brain Res 1274:66-76.

Reuter S, Gupta SC, Chaturvedi MM, Aggarwal BB. 2010. Oxidative stress, inflammation, and cancer: How are they linked? Free Radic Biol Med 49:1603-1616.

Robinson RA, Evans AR. 2012. Enhanced sample multiplexing for nitrotyrosine-modified proteins using combined precursor isotopic labeling and isobaric tagging. Anal Chem 84:4677-4686.

Robinson RA, Lange MB, Sultana R, Galvan V, Fombonne J, Gorostiza O, Zhang J, Warrier G, Cai J, Pierce WM, Bredesen DE, Butterfield DA. 2011. Differential expression and redox proteomics analyses of an Alzheimer disease transgenic mouse model: Effects of the amyloid-beta peptide of amyloid precursor protein. Neuroscience 177:207-222.

Roe MR, Griffin TJ. 2006. Gel-free mass spectrometry-based high throughput proteomics: Tools for studying biological response of proteins and proteomes. Proteomics 6:4678-4687.

Roe MR, Xie H, Bandhakavi S, Griffin TJ. 2007. Proteomic mapping of 4hydroxynonenal protein modification sites by solid-phase hydrazide chemistry and mass spectrometry. Anal Chem 79:3747-3756.

Ross PL, Huang YN, Marchese JN, Williamson B, Parker K, Hattan S, Khainovski N, Pillai S, Dey S, Daniels S, Purkayastha S, Juhasz P, Martin S, Bartlet-Jones M, He F, Jacobson A, Pappin DJ. 2004. Multiplexed protein quantitation in Saccharomyces cerevisiae using amine-reactive isobaric tagging reagents. Mol Cell Proteomics 3:1154-1169.

Saha S, Guillily MD, Ferree A, Lanceta J, Chan D, Ghosh J, Hsu CH, Segal L, Raghavan K, Matsumoto K, Hisamoto N, Kuwahara T, Iwatsubo T, Moore L, Goldstein L, Cookson M, Wolozin B. 2009. LRRK2 modulates vulnerability to mitochondrial dysfunction in Caenorhabditis elegans. J Neurosci 29:9210-9218.

Schopfer FJ, Baker PR, Freeman BA. 2003. NO-dependent protein nitration: A cell signaling event or an oxidative inflammatory response? Trends Biochem Sci 28:646-654.

Scibior-Bentkowska D, Czeczot H. 2009. [Cancer cells and oxidative stress]. Postepy Hig Med Dosw (Online) 63:58-72. 
Shacter E, Williams JA, Lim M, Levine RL. 1994. Differential susceptibility of plasma proteins to oxidative modification: Examination by western blot immunoassay. Free Radic Biol Med 17:429-437.

Shao CH, Capek HL, Patel KP, Wang M, Tang K, DeSouza C, Nagai R, Mayhan W, Periasamy M, Bidasee KR. 2011. Carbonylation contributes to SERCA2a activity loss and diastolic dysfunction in a rat model of type 1 diabetes. Diabetes 60:947-959.

Shaw PJ, Ince PG, Falkous G, Mantle D. 1995. Oxidative damage to protein in sporadic motor neuron disease spinal cord. Ann Neurol 38:691-695.

Sheehan D. 2006. Detection of redox-based modification in two-dimensional electrophoresis proteomic separations. Biochem Biophys Res Commun 349:455-462.

Sheehan D, McDonagh B, Barcena JA. 2010. Redox proteomics. Expert Rev Proteomics 7:1-4.

Shibata N, Nagai R, Uchida K, Horiuchi S, Yamada S, Hirano A, Kawaguchi M, Yamamoto T, Sasaki S, Kobayashi M. 2001. Morphological evidence for lipid peroxidation and protein glycoxidation in spinal cords from sporadic amyotrophic lateral sclerosis patients. Brain Res 917:97-104.

Slade PG, Williams MV, Brahmbhatt V, Dash A, Wishnok JS, Tannenbaum SR. 2010. Proteins modified by the lipid peroxidation aldehyde 9,12dioxo-10(E)-dodecenoic acid in MCF7 breast cancer cells. Chem Res Toxicol 23:557-567.

Smith MA, Richey Harris PL, Sayre LM, Beckman JS, Perry G. 1997. Widespread peroxynitrite-mediated damage in Alzheimer's disease. J Neurosci 17:2653-2657.

Snell RG, Macmillan JC, Cheadle JP, Fenton I, Lazarou LP, Davies P, Macdonald ME, Gusella JF, Harper PS, Shaw DJ. 1993. Relationship between trinucleotide repeat expansion and phenotypic variation in Huntington's disease. Nat Genet 4:393-397.

Soderling AS, Ryberg H, Gabrielsson A, Larstad M, Toren K, Niari S, Caidahl K. 2003. A derivatization assay using gas chromatography/ negative chemical ionization tandem mass spectrometry to quantify 3nitrotyrosine in human plasma. J Mass Spectrom 38:1187-1196.

Sorolla MA, Reverter-Branchat G, Tamarit J, Ferrer I, Ros J, Cabiscol E. 2008. Proteomic and oxidative stress analysis in human brain samples of Huntington disease. Free Radic Biol Med 45:667-678.

Sorolla MA, Rodriguez-Colman MJ, Tamarit J, Ortega Z, Lucas JJ, Ferrer I, Ros J, Cabiscol E. 2010. Protein oxidation in Huntington disease affects energy production and vitamin B6 metabolism. Free Radic Biol Med 49:612-621.

Stadtman ER, Berlett BS. 1998. Reactive oxygen-mediated protein oxidation in aging and disease. Drug Metab Rev 30:225-243.

Stadtman ER, Levine RL. 2003. Free radical-mediated oxidation of free amino acids and amino acid residues in proteins. Amino Acids 25:207218.

Stadtman ER, Oliver CN, Levine RL, Fucci L, Rivett AJ. 1988. Implication of protein oxidation in protein turnover, aging, and oxygen toxicity. Basic Life Sci 49:331-339.

Subramaniam R, Roediger F, Jordan B, Mattson MP, Keller JN, Waeg G, Butterfield DA. 1997. The lipid peroxidation product, 4-hydroxy-2trans-nonenal, alters the conformation of cortical synaptosomal membrane proteins. J Neurochem 69:1161-1169.

Sultana R, Butterfield DA. 2009. Proteomics identification of carbonylated and HNE-bound brain proteins in Alzheimer's disease. Methods Mol Biol 566:123-135.

Sultana R, Boyd-Kimball D, Poon HF, Cai J, Pierce WM, Klein JB, Markesbery WR, Zhou XZ, Lu KP, Butterfield DA. 2006a. Oxidative modification and down-regulation of Pin1 in Alzheimer's disease hippocampus: A redox proteomics analysis. Neurobiol Aging 27:918925.

Sultana R, Boyd-Kimball D, Poon HF, Cai J, Pierce WM, Klein JB, Merchant M, Markesbery WR, Butterfield DA. 2006b. Redox proteomics identification of oxidized proteins in Alzheimer's disease hippocampus and cerebellum: An approach to understand pathological and biochemical alterations in AD. Neurobiol Aging 27:1564-1576.
Sultana R, Poon HF, Cai J, Pierce WM, Merchant M, Klein JB, Markesbery WR, Butterfield DA. 2006c. Identification of nitrated proteins in Alzheimer's disease brain using a redox proteomics approach. Neurobiol Dis 22:76-87.

Sultana R, Reed T, Perluigi M, Coccia R, Pierce WM, Butterfield DA. 2007. Proteomic identification of nitrated brain proteins in amnestic mild cognitive impairment: A regional study. J Cell Mol Med 11:839-851.

Sultana R, Perluigi M, Newman SF, Pierce WM, Cini C, Coccia R, Butterfield DA. 2010. Redox proteomic analysis of carbonylated brain proteins in mild cognitive impairment and early Alzheimer's disease. Antioxid Redox Signal 12:327-336.

Sultana R, Perluigi M, Allan Butterfield D. 2012. Lipid peroxidation triggers neurodegeneration: A redox proteomics view into the Alzheimer disease brain. Free Radic Biol Med (in press).

Szweda PA, Friguet B, Szweda LI. 2002. Proteolysis, free radicals, and aging. Free Radic Biol Med 33:29-36.

Tabner BJ, El-Agnaf OM, German MJ, Fullwood NJ, Allsop D. 2005. Protein aggregation, metals and oxidative stress in neurodegenerative diseases. Biochem Soc Trans 33:1082-1086.

Thongboonkerd V, Malasit P. 2005. Renal and urinary proteomics: Current applications and challenges. Proteomics 5:1033-1042.

Timms JF, Cramer R. 2008. Difference gel electrophoresis. Proteomics 8:4886-4897.

Tsaytler PA, M COF, Sakharov DV, Krijgsveld J, Egmond MR. 2008. Immediate protein targets of photodynamic treatment in carcinoma cells. J Proteome Res 7:3868-3878.

Turchan J, Pocernich CB, Gairola C, Chauhan A, Schifitto G, Butterfield DA, Buch S, Narayan O, Sinai A, Geiger J, Berger JR, Elford H, Nath A. 2003. Oxidative stress in HIV demented patients and protection ex vivo with novel antioxidants. Neurology 60:307-314.

Turner C, Schapira AH. 2010. Mitochondrial matters of the brain: The role in Huntington's disease. J Bioenerg Biomembr 42:193-198.

Tyther R, Ahmeda A, Johns E, Sheehan D. 2007. Proteomic identification of tyrosine nitration targets in kidney of spontaneously hypertensive rats. Proteomics 7:4555-4564.

Tyther R, Ahmeda A, Johns E, McDonagh B, Sheehan D. 2010. Proteomic profiling of perturbed protein sulfenation in renal medulla of the spontaneously hypertensive rat. J Proteome Res 9:2678-2687.

Unlu M, Morgan ME, Minden JS. 1997. Difference gel electrophoresis: A single gel method for detecting changes in protein extracts. Electrophoresis 18:2071-2077.

Van Laar VS, Dukes AA, Cascio M, Hastings TG. 2008. Proteomic analysis of rat brain mitochondria following exposure to dopamine quinone: Implications for Parkinson disease. Neurobiol Dis 29:477-489.

Varadarajan S, Yatin S, Aksenova M, Butterfield DA. 2000. Review: Alzheimer's amyloid beta-peptide-associated free radical oxidative stress and neurotoxicity. J Struct Biol 130:184-208.

Victor KG, Rady JM, Cross JV, Templeton DJ. 2012. Proteomic profile of reversible protein oxidation using PROP, purification of reversibly oxidized proteins. PLoS ONE 7:e32527.

Vila A, Tallman KA, Jacobs AT, Liebler DC, Porter NA, Marnett LJ. 2008. Identification of protein targets of 4-hydroxynonenal using click chemistry for ex vivo biotinylation of azido and alkynyl derivatives. Chem Res Toxicol 21:432-444.

Vitek MP, Bhattacharya K, Glendening JM, Stopa E, Vlassara H, Bucala R, Manogue K, Cerami A. 1994. Advanced glycation end products contribute to amyloidosis in Alzheimer disease. Proc Natl Acad Sci USA 91:4766-4770.

Wilson CH, Zeile S, Chataway T, Nieuwenhuijs VB, Padbury RT, Barritt GJ. 2011. Increased expression of peroxiredoxin 1 and identification of a novel lipid-metabolizing enzyme in the early phase of liver ischemia reperfusion injury. Proteomics 11:4385-4396.

Witko-Sarsat V, Friedlander M, Capeillere-Blandin C, Nguyen-Khoa T, Nguyen AT, Zingraff J, Jungers P, Descamps-Latscha B. 1996. Advanced oxidation protein products as a novel marker of oxidative stress in uremia. Kidney Int 49:1304-1313. 
Wittmann-Liebold B, Graack HR, Pohl T. 2006. Two-dimensional gel electrophoresis as tool for proteomics studies in combination with protein identification by mass spectrometry. Proteomics 6:4688-4703.

Wu CL, Chou HC, Cheng CS, Li JM, Lin ST, Chen YW, Chan HL. 2012. Proteomic analysis of UVB-induced protein expression- and redoxdependent changes in skin fibroblasts using lysine- and cysteinelabeling two-dimensional difference gel electrophoresis. J Proteomics 75:1991-2014.

Yagi H, Katoh S, Akiguchi I, Takeda T. 1988. Age-related deterioration of ability of acquisition in memory and learning in senescence accelerated mouse: SAM-P/8 as an animal model of disturbances in recent memory. Brain Res 474:86-93.

Yan LJ, Forster MJ. 2011. Chemical probes for analysis of carbonylated proteins: A review. J Chromatogr B Analyt Technol Biomed Life Sci 879:1308-1315.

Yeo WS, Lee SJ, Lee JR, Kim KP. 2008. Nitrosative protein tyrosine modifications: Biochemistry and functional significance. BMB Rep 41:194-203.
Ying J, Clavreul N, Sethuraman M, Adachi T, Cohen RA. 2007. Thiol oxidation in signaling and response to stress: Detection and quantification of physiological and pathophysiological thiol modifications. Free Radic Biol Med 43:1099-1108.

Yoo BS, Regnier FE. 2004. Proteomic analysis of carbonylated proteins in two-dimensional gel electrophoresis using avidin-fluorescein affinity staining. Electrophoresis 25:1334-1341.

Yorek MA. 2003. The role of oxidative stress in diabetic vascular and neural disease. Free Radic Res 37:471-480.

Yoritaka A, Hattori N, Uchida K, Tanaka M, Stadtman ER, Mizuno Y. 1996. Immunohistochemical detection of 4-hydroxynonenal protein adducts in Parkinson disease. Proc Natl Acad Sci USA 93:2696-2701.

Yu HL, Chertkow HM, Bergman H, Schipper HM. 2003. Aberrant profiles of native and oxidized glycoproteins in Alzheimer plasma. Proteomics 3:2240-2248.

Zhu Y, Carvey PM, Ling Z. 2006. Age-related changes in glutathione and glutathione-related enzymes in rat brain. Brain Res 1090:35-44. 